\title{
Online Monitoring Technical Basis and Analysis Framework for Large Power Transformers; Interim Report for FY 2012
}

Nancy J. Lybeck

Vivek Agarwal

Binh T. Pham

Heather D. Medema

Kirk Fitzgerald

September 2012

Idaho National

operated by Battelle Energy Alliance 


\section{DISCLAIMER}

This information was prepared as an account of work sponsored by an agency of the U.S. Government. Neither the U.S. Government nor any agency thereof, nor any of their employees, makes any warranty, expressed or implied, or assumes any legal liability or responsibility for the accuracy, completeness, or usefulness, of any information, apparatus, product, or process disclosed, or represents that its use would not infringe privately owned rights. References herein to any specific commercial product,

process, or service by trade name, trade mark, manufacturer, or otherwise, does not necessarily constitute or imply its endorsement, recommendation, or favoring by the U.S. Government or any agency thereof. The views and opinions of authors expressed herein do not necessarily state or reflect those of the U.S. Government or any agency thereof. 


\title{
Online Monitoring Technical Basis and Analysis Framework for Large Power Transformers; Interim Report for FY 2012
}

\author{
Nancy J. Lybeck \\ Vivek Agarwal \\ Binh T. Pham \\ Heather D. Medema \\ Kirk Fitzgerald
}

September 2012

\begin{abstract}
Idaho National Laboratory Idaho Falls, Idaho 83415

http://www.inl.gov
\end{abstract}

Prepared for the

U.S. Department of Energy

Office of Nuclear Energy

Under DOE Idaho Operations Office

Contract DE-AC07-05ID14517 



\begin{abstract}
The Light Water Reactor Sustainability program at Idaho National Laboratory (INL) is actively conducting research to develop and demonstrate online monitoring capabilities for active components in existing nuclear power plants. A pilot project is currently underway to apply these capabilities to generator step-up transformers (GSUs) and emergency diesel generators (EDGs). INL and the Electric Power Research Institute (EPRI) are working jointly to implement the pilot project. The EPRI Fleet-Wide Prognostic and Health Management (FW-PHM) Software Suite will be used to implement monitoring in conjunction with utility partners: the Shearon Harris Nuclear Generating Station (owned by Duke Energy Progress) for GSUs, and the Braidwood Generating Station (owned by Exelon Corporation) for EDGs.

This report presents monitoring techniques, fault signatures, and diagnostic and prognostic models for GSUs. GSUs are main transformers that are directly connected to generators, stepping up the voltage from the generator output voltage to the highest transmission voltages for supplying electricity to the transmission grid. Technical experts from Shearon Harris are assisting INL and EPRI in identifying critical faults and defining fault signatures associated with each fault. The resulting diagnostic models will be implemented in the FW-PHM Software Suite and tested using data from Shearon Harris. Parallel research on EDGs is being conducted, and will be reported in an interim report during the first quarter of fiscal year 2013.
\end{abstract}




\section{EXECUTIVE SUMMARY}

The Light Water Reactor Sustainability Program is a research, development, and deployment program sponsored by the U.S. Department of Energy Office of Nuclear Energy. The program is operated in collaboration with the Electric Power Research Institute's (EPRI's) research and development efforts in the Long-Term Operations (LTO) Program. The LTO Program is managed as a separate technical program operating in the Plant Technology Department of the EPRI Nuclear Power Sector with the guidance of an industry advisory Integration Committee. Because both the Department of Energy Office of Nuclear Energy and EPRI conduct research and development in technologies that have application to establishing the feasibility of operating commercial light water reactors (LWRs) beyond the current 60-year license limits, it is important that the work be coordinated to the benefit of both organizations.

The Light Water Reactor Sustainability and LTO Programs are working closely with nuclear utilities to develop instrumentation and control technologies and solutions to help ensure the safe life extension of current reactors. One of the main areas of focus is centralized online monitoring (OLM), which has two subprojects: online monitoring of active components and online monitoring of passive components. The research activities associated with online monitoring of active components are presented here. The current fleet of nuclear power plants (NPPs) performs periodic or condition-based maintenance of their active assets/components. The objective of centralized OLM is to implement predictive online monitoring techniques that would enable NPPs to diagnose incipient faults, perform proactive maintenance, and estimate the remaining useful life (RUL) of the asset.

To demonstrate the value of predictive online monitoring, EPRI has developed a Web-based Fleet-wide Prognostic and Health Management (FWPHM) Software Suite (Beta Version 1.1). The framework of the FW-PHM software consists of four main components: Diagnostic Advisor; Asset Fault Signature (AFS) Database; RUL Advisor; and RUL Signature Database. Idaho National Laboratory (INL) is responsible for performing beta testing of the software. This work includes installation and configuration process evaluation; content-based testing; data synchronization; and a human factors evaluation.

Part of the long-term strategic goal of centralized OLM of active components is to enable industry to implement online monitoring using the FW-PHM software on selected active components. Generator Step-Up Transformers (GSUs) and Emergency Diesel Generators (EDGs) are two specified active components for which monitoring techniques, diagnostic and prognostic models will be developed in the software. INL and EPRI have identified a partner utility for each active component. Braidwood Generating Station (owned by Exelon Corporation) and Shearon Harris Nuclear Generating Station (owned by Duke Energy Progress) are partner utilities for EDGs and GSUs respectively.

Along with beta testing of the FW-PHM software, INL is working with the partner utilities to identify and characterize critical faults that lead to catastrophic failures in both GSUs and EDGs. This will allow INL to populate the AFS database of the FW-PHM software. The AFS database captures details about asset type, source of the fault information, different fault signatures, causes, 
remedies, and consequences. Based on the identified fault signatures and failure modes, the Diagnostic Advisor is used to diagnose fault conditions.

INL will research diagnostic and prognostic models for GSUs and EDGs over the next two years. These models will be used to populate the RUL database and to make component life predictions using the RUL advisor. The resulting models will be used with data from the utility partners to demonstrate the use of predictive OLM in NPPs. The FW-PHM software is unique in the sense that it standardizes the diagnostic and prognostic approach across assets based on fault signatures and fault features, generates a comprehensive diagnosis report, and allows information sharing between different NPPs via a master database. These capabilities do not currently exist in NPPs, and are expected to support safer long term operation of the NPPs. 


\section{ACKNOWLEDGEMENTS}

The authors thank Rick Rusaw (EPRI) for providing the FW-PHM Software Suite (Beta Version 1.1) and recognize his efforts to identify and establish collaboration with partner utilities. They are grateful to Randy Bickford (Expert Microsystem Inc.) for providing technical support and training on the software. They also thank Gary Deck (System Engineer at Braidwood Generating Station), Greg Young (System Engineer at Shearon Harris Nuclear Generating Station), and Michael A. Bodnar (Lead Engineer, at Duke Energy Progress) for their hospitality and for and participating in the initial development of monitoring information for GSUs. 


\section{CONTENTS}

ABSTRACT.

EXECUTIVE SUMMARY . v

ACKNOWLEDGEMENTS . vii

ACRONYMS xii

1. INTRODUCTION 1

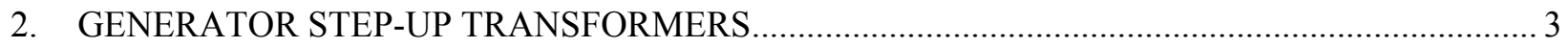

2.1 Major Components of Transformers ................................................................................... 3

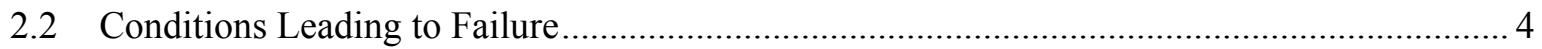

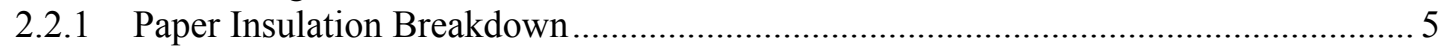

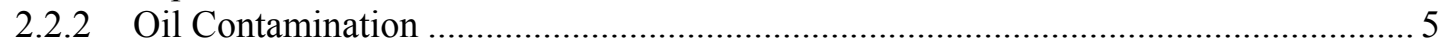

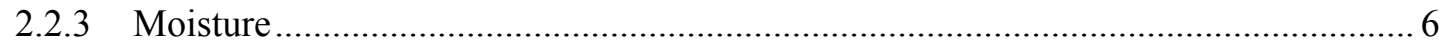

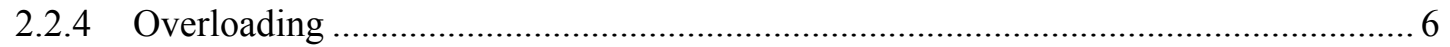

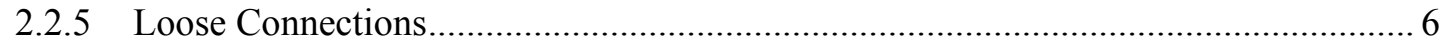

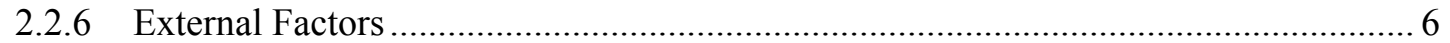

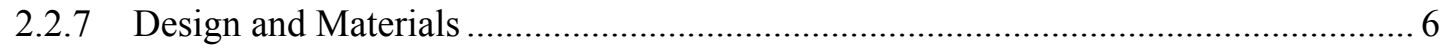

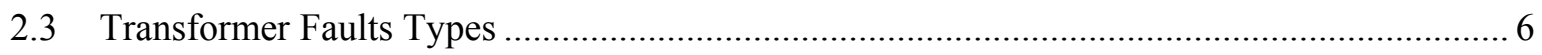

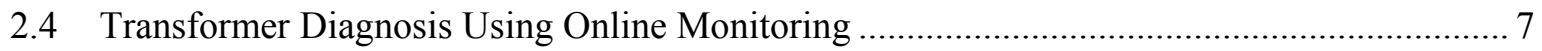

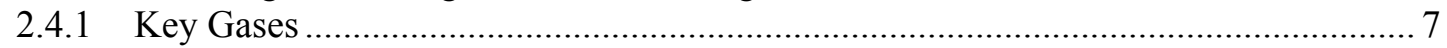

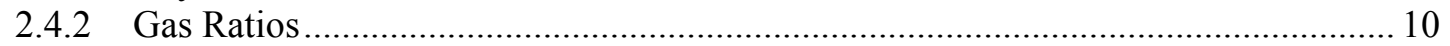

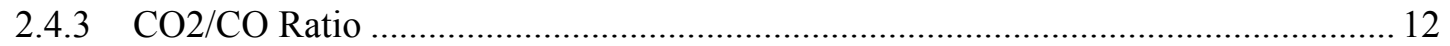

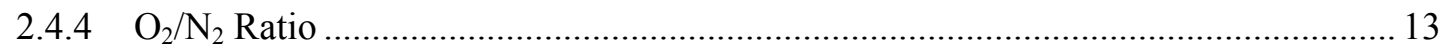

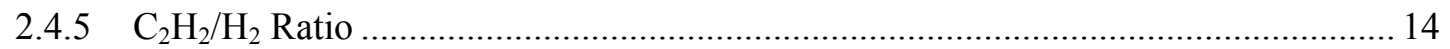

2.5 Deenergized Transformer Testing............................................................................. 14

2.6 Diagnostic Techniques for Fault Classification ................................................................ 15

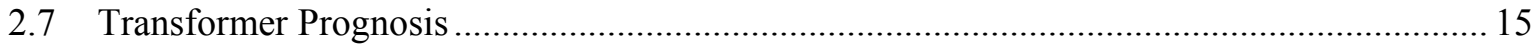

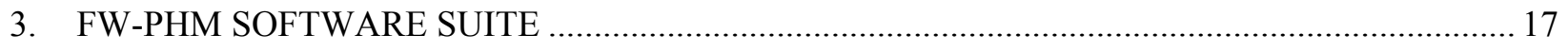

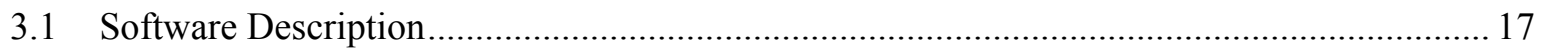

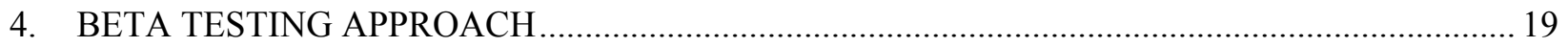

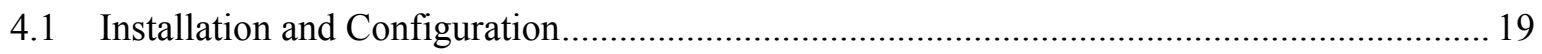

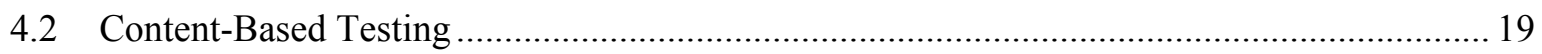

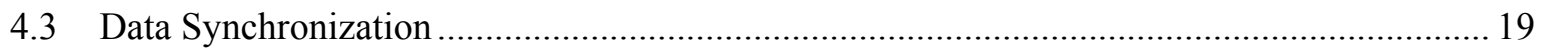

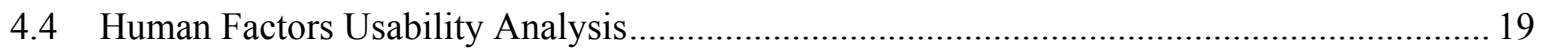

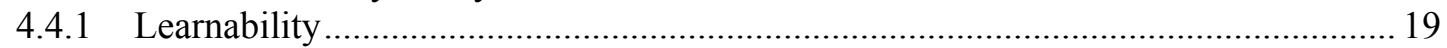

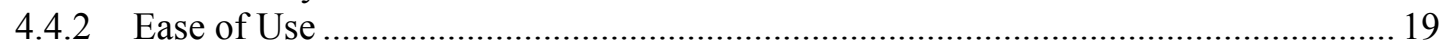

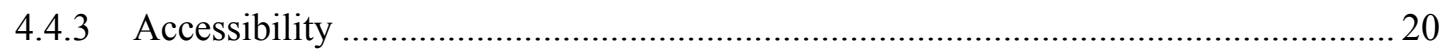

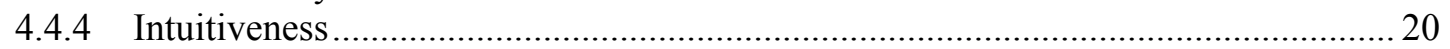

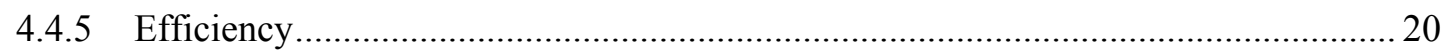

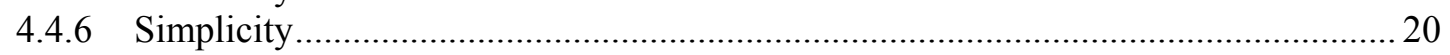

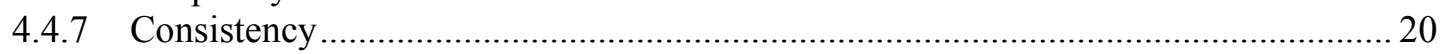




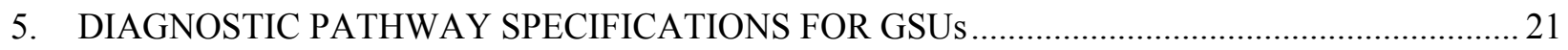

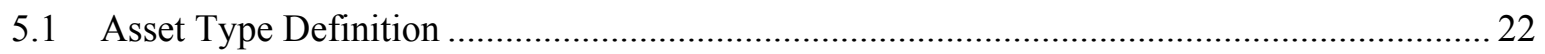

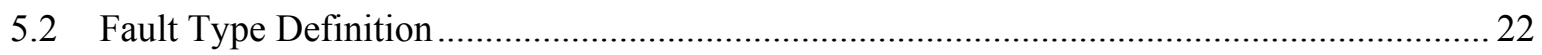

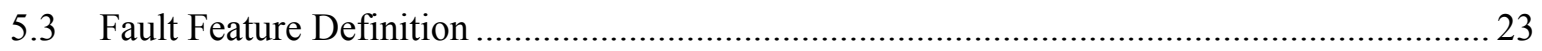

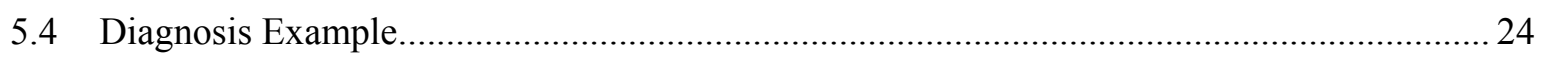

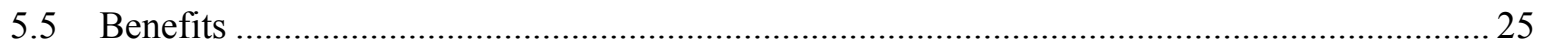

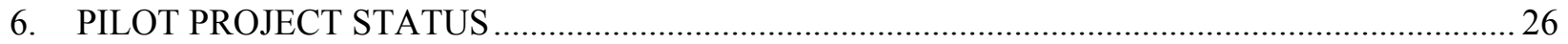

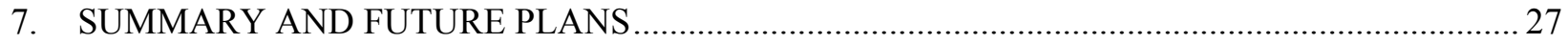

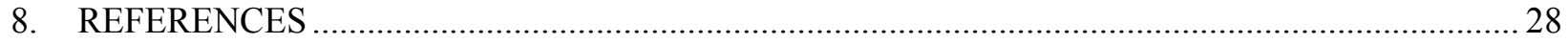

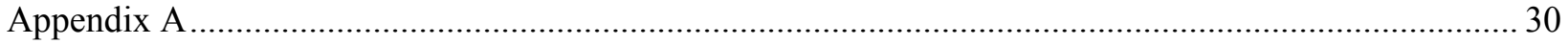

FIGURES

Figure 1. Frequency and severity of transformer failure in terms of cost [Bartley 2003]......................... 5

Figure 2. Gas composition for partial discharge and arcing faults [EPRI 2006b] ................................. 9

Figure 3. Characteristic composition of gases generated because of overheating of oil and paper, corona, and arcing (Morgan Schaffer Systems)....................................................................... 9

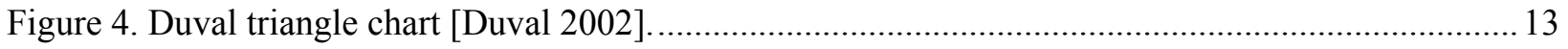

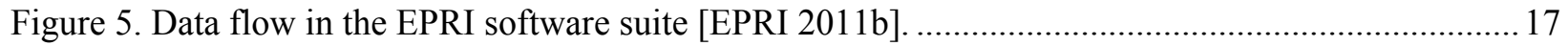

Figure 6. EPRI master database and user local database aggregation and periodic master database

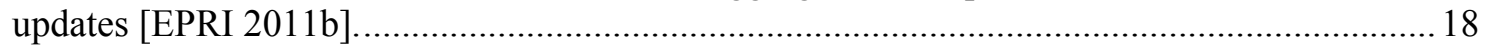

Figure 7. Different Attributes of fault signature [EPRI 2012] ........................................................... 21

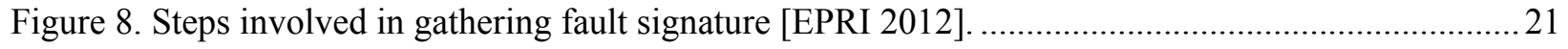

Figure 9. List of fault features for oil pump motor fault types. ........................................................... 24

Figure 10. Possible diagnosis of oil motor pump using the FW-PHM..................................................25

\section{TABLES}

Table 1. Concerns associated with major components of transformers................................................. 4

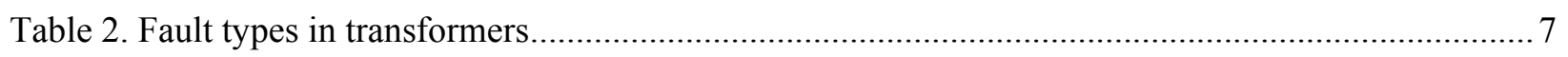

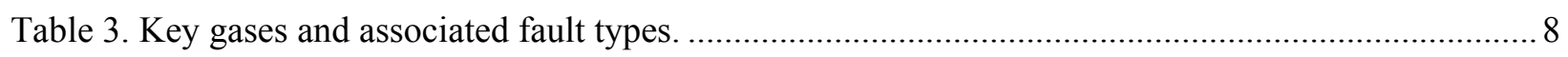

Table 4. Gas generation at different temperature [EPRI 2006b]........................................................ 10

Table 5. The values are derived from information provided within [IEEE 1978] .................................. 10

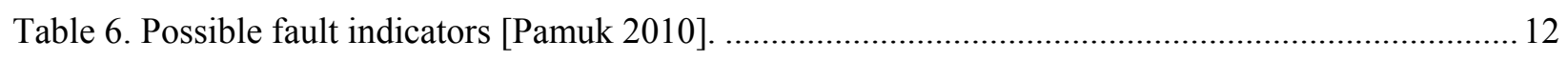

Table 7. Ranges for Doernenberg and Rogers ratios [Hamrick 2010]................................................ 13

Table 8. Failure modes and contributing fault types considered.......................................................... 22

Table 9. Summary of fault features used to diagnose fault types considered.........................................2 23 
Table A1. Winding Insulation Degradation Fault Signature - General Specification. ............................29

Table A2. Operating at High Temperature for Long Period. Technology: Operating History. ..................31

Table A3. Insulation Oil Degradation Fault Signature - General Specification...................................... 32

Table A4. Loss of Dielectric Strength Oil Fault Feature - Technology: Oil analysis. ............................. 33

Table A5. Insulation Oil Acidity Fault Signature - General Specification. ............................................ 34

Table A6. Acidity of Oil Fault Feature - Technology: Oil analysis....................................................... 35

Table A7. Insulation Oil Contamination Fault Signature - General Specification.................................... 36

Table A8. Interfacial Tension of Oil Fault Feature - Technology: Oil analysis........................................ 37

Table A9. Table A1. Loss of Dielectric Strength of Bushing Fault Signature - General

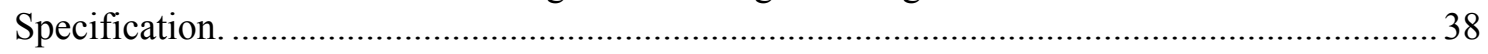

Table A10. Doble Capacitance Fault Feature - Technology: Doble Analysis. ........................................ 39

Table A11. Oil Pump Motor Performance Loss - General Specification.................................................. 40

Table A12. Motor Current Abnormal Value: Fault Feature. ................................................................... 41

Table A13. Motor Insulation Resistance Megger Inspection: Fault Feature. ............................................. 42 


\section{ACRONYMS}

ANSI American National Standards Institute

AE Acoustic Emission

AFS asset fault signature

ASTM American Society for Testing and Materials

CBM condition based monitoring

CPT The Center for Photonics Technology

DGA dissolved gas analysis

DETC deenergized tap changer

DP degree of polymerization

EDG emergency diesel generator

EPRI Electric Power Research Institute

FW-PHM fleet-wide prognostic and health monitoring

GSU generator step-up transformer

IEC International Electrotechnical Commission

IEEE Institute of Electrical and Electronics Engineer

IFT interfacial tension

INL Idaho National Laboratory

KISS keep it simple stupid

K-NN k-nearest neighbors

LWR light water reactor

LTC load tap changer

LTO Long-Term Operations (Program)

NPP nuclear power plant

OLM online monitoring

PDC polarization/depolarization current

RUL remaining useful life

UHF ultra-high frequency 


\section{Online Monitoring Technical Basis and Analysis Framework for Large Power Transformers; Interim Report for FY 2012}

\section{INTRODUCTION}

The Light Water Reactor Sustainability Program is a research, development, and deployment program sponsored by the U.S. Department of Energy Office of Nuclear Energy. The program is operated in collaboration with the Electric Power Research Institute's (EPRI's) research and development efforts in the Long-Term Operations (LTO) Program. The LTO Program is managed as a separate technical program operating in the Plant Technology Department of the EPRI Nuclear Power Sector, with the guidance of an industry advisory integration committee. Because both the Department of Energy Office of Nuclear Energy and EPRI conduct research and development in technologies that have application to establishing the feasibility of operating commercial light water reactors (LWRs) beyond the current 60 -year license limits, it is important that the work be coordinated to the benefit of both organizations.

The Light Water Reactor Sustainability and LTO Programs are working closely with nuclear utilities to develop instrumentation and control technologies and solutions to help ensure the safe life extension of current reactors. One of the main areas of focus is centralized online monitoring (OLM). The centralized OLM project has two subprojects: online monitoring of active components and online monitoring of passive components.

Within the OLM of active components pilot project, generator step-up transformers (GSUs) and emergency diesel generators (EDGs) are the two active components selected for which fault signatures, diagnostic models, and prognostic models will be developed and implemented in existing nuclear power plants (NPPs). The interim status of research activities associated with OLM for GSUs is presented in this report. Parallel research on EDGs is being conducted and will be summarized in a separate interim report during first quarter of FY 2013.

The current fleet of NPPs mostly performs periodic or condition based maintenance of their transformers. The disadvantage of periodic health assessment is that the time interval between two consecutive maintenance activities is not always sufficient to identify developing issues prior to failure. Periodic maintenance is often performed when the transformer is not in service or the plant is in outage. Moreover, the actual state of the transformer with respect to time and plant operation condition is often not available for diagnosis. Periodic maintenance also frequently results in the maintenance of healthy transformer components, increasing maintenance costs, and the possibility of human error.

Another technique used for assessing transformer health is condition based monitoring (CBM), a reactive regime in which transformer maintenance is performed when a fault is identified based on monitored parameters and state knowledge. CBM has been shown to reduce maintenance costs by reducing the number of maintenance operations and the resulting possibility of human error.

The long-term objective of the OLM pilot project for active components is to implement predictive online monitoring techniques that would enable NPPs to diagnose incipient faults, perform proactive maintenance, and estimate the remaining useful life (RUL) of their active assets. Predictive or proactive maintenance involves predicting future parameter values (or the actual state of the transformer). This allows maintainers to take timely or proactive action before the occurrence of a catastrophic failure and to estimate and optimize future maintenance costs.

EPRI is leading the effort to achieve the project objective in collaboration with Idaho National Laboratory (INL). EPRI has developed the Fleet-Wide Prognostic and Health Monitoring (FW-PHM) Software Suite (Beta Version 1.1) for predictive online monitoring of active assets. The open-architecture integrated FW-PHM software has four main components: 
- Diagnostic Advisor. Identifies impending failures by comparing asset fault signatures (AFS) with operating data

- AFS Database. Organizes asset fault signatures collected from across the industry

- RUL Advisor. Estimates how long an aging or faulty asset will continue to provide reliable service

- RUL Signature Database. Organizes asset remaining life signatures collected from across the industry.

Part of the long-term objective of the OLM of active components pilot project is to enable the nuclear industry to implement online monitoring using the FW-PHM software on selected active components such as GSUs. Prior to the implementation of the software by the industry, INL is performing beta testing of the FW-PHM Software Suite. Beta testing will encompass installation and configuration, content-based testing, data synchronization, and a human factors usability analysis.

GSUs are the main transformers that are directly connected to generators, stepping up the voltage from the generator output voltage to the highest transmission voltages for supplying electricity to the transmission grid. Identification and classification of different fault types in GSUs is a challenging task because there are several factors that contribute to transformer degradation that may eventually lead to catastrophic failure. These factors are associated with transformer age, operating conditions, and stressors acting on the transformers. Dissolved gas analysis (DGA) has been found to be one of the most effective online diagnostic tools. The information collected via DGA can also be used to estimate the RUL of transformers. Implementation of OLM on GSUs based on DGA will enable utilities to diagnose incipient faults, perform proactive maintenance, prevent unexpected catastrophic failure, minimize maintenance cost, and improve plant economic competitiveness.

INL and EPRI have identified Shearon Harris Nuclear Generating Station (owned by Duke Energy Progress) as a utility partner for GSUs. The monitoring information from the plant GSUs will be used to define fault signatures associated with common fault types. These fault signatures will be entered in the AFS database and will be used by the Diagnostic Advisor of the FW-PHM software to identify impending failures.

This report is organized as follows. Background information on GSUs is introduced in Section 2, including faults types, diagnostic techniques, and prognostic models. Section 3 briefly describes the FWPHM software suite. An overview of the beta testing process is presented in Section 4. Diagnostic fault signatures for GSUs are presented in Section 5. The status of the pilot project and progress made with partner utilities is provided in Section 6. The current state of research and future plans are summarized in Section 7. 


\section{GENERATOR STEP-UP TRANSFORMERS}

There are many different types of transformers. The basic principles of design, operation, and maintenance apply across all transformer types, but there are significant differences in some areas, particularly in application. EPRI has compiled a guidebook based on accumulated knowledge of transformer design principles, operations, maintenance, and performance [EPRI 2011a]. This section focuses on online monitoring of GSUs (also known as unit transformers or main transformers).

GSUs, which are directly connected to generators, step up the voltage from the generator output voltage (on the order of $24 \mathrm{kV}$ ) to the highest transmission voltages for supplying electricity to the transmission grid. The GSUs are physically the largest transformers in the system and are available in single-phase or three-phase units. The primary winding (generator voltage) is connected in delta to minimize the coil current and provide winding stabilization, and the secondary winding (grid voltage) is connected in wye to minimize the coil voltage. The primary winding current can be as much as $40 \mathrm{kA}$, and many special considerations in design and manufacture are required. The GSU generally will not have a load tap changer (LTC) because regulation can be achieved at the generator, although some utilities do require their GSUs to be equipped with LTCs. Most utilities, however, will require the GSU to be equipped with deenergized tap changers (DETCs). GSUs used in nuclear and large coal fired power plants are usually operated continuously at a constant load near the full rating. This means that they are generally operated at rated temperature and therefore age more quickly than most other transformers. GSUs often are not protected by a circuit breaker, meaning fault currents can be sustained longer than for other transformers and large over voltages can occur from generator loss of load. When generator breakers or disconnects are present, the GSUs can also be used to power auxiliary systems from the grid.

\subsection{Major Components of Transformers}

Most transformers consist of the following basic components:

1. Core. Transformer cores are built up of many thin laminations of cold-rolled, grain-oriented, silicon steel (typically .009 to .014 in. thick) to minimize eddy loss. Rectangular and cruciform are two types of core construction.

2. Winding. The basic winding conductors are rectangular in shape. Each individual winding conductor is known as a strand, and is insulated by cellulose paper. There are three basic categories of winding designs used in core form transformers (helical, disk, and layer), but there are many variations within these basic categories. Some portion of the winding is used to increase or decrease the turns, so that the output voltage can be regulated. This portion of winding is known as the tap winding.

3. Main Oil Tank. Tanks are designed differently for core-type and shell-type transformers. All tanks are designed to withstand full vacuum and 15 psi internal pressure to facilitate proper processing of the core and coil assemblies, and are filled with oil under vacuum at the time of installation. They must also withstand the maximum operating pressure under all operating conditions plus the weight of the oil column inside the tank.

4. Load tap changer. ${ }^{\text {a }}$ The LTC is a switching device equipped with current-carrying contacts that are connected to the regulating winding (frequently called a tap winding) of a transformer. Its purpose is to change the transformer turn ratio and, thereby, the voltage while under load without interruption to the power flow. The turn ratio is changed by either adding to or subtracting from turns of the regulating winding.

5. Deenergized tap changer. The DETC is commonly called a no-load tap changer (a misnomer, because this type of tap changer can only be operated when the transformer is deenergized, not just 
operating at no load). The purpose of a DETC is to be able to change the output voltage by changing the transformer turn ratio. A standard DETC has five positions, including the neutral position.

6. Bushings. The two most common types of bushings are solid porcelain bushings on smaller transformers and oil-filled bushings on larger transformers such as GSUs. Bushings are a critical link between the windings and the outside power delivery system. For high-voltage applications, like GSUs, bushings are generally the oil-filled capacitance graded type. This type of bushing has a central conductor surrounded by an oil impregnated capacitance graded core, which is encased by upper and lower insulators and a metal flange assembly.

7. Cooling equipment. Transformers in general have a self-cooled rating (cooling because of convection and radiation) and a forced-cooled rating (fans and/or pumps). GSUs do not have a self-cooled rating as they are operated fully loaded most of the time. The cooling process within the transformer is accomplished by the flow of oil out of the top of the transformer, through the heat exchanger, through the pump, and into the bottom of the transformer.

Monitoring the operating condition (health) of the above-mentioned components contributes to the overall health of the transformer. Each component has its own individual concerns that may result in its failure. The concerns listed in Table 1 require special attention in aging transformers. The observations or parameters associated with these concerns, and techniques to measure them, are discussed in Section 2.2.

Table 1. Concerns associated with major components of transformers.

\begin{tabular}{|ll|}
\hline \multicolumn{1}{|c|}{ Components } & \multicolumn{1}{c|}{ Concerns } \\
\hline Core & Loose core lamination; general core heating; unintentional core grounding \\
Windings & Insulation deterioration; dielectric failure; static electrification; local heating \\
Main oil tank & Oil contamination; loss of dielectric strength; corrosive sulfur; oil level \\
Oil filled bushing & $\begin{array}{l}\text { Insulation overheating; loss of seal/moisture ingress; delamination; surface } \\
\text { tracking; oil leaks }\end{array}$ \\
LTC/DETC & $\begin{array}{l}\text { Contact wear, bending, and overheating; oil deterioration; in-tank LTC oil leakage; } \\
\text { improper operation; excessive voltage swings }\end{array}$ \\
Cooling equipment & Excessive wear of bearing; physical damage; temperature \\
\hline
\end{tabular}

\subsection{Conditions Leading to Failure}

As transformers age their ability to sustain the impact of stressors such as loading, increase in operating temperature, etc., decreases, making them more susceptible to failure. There are several factors that contribute to the degradation of transformer performance, and may eventually lead to failure. Some of the common causes include paper insulation breakdown; oil contamination; moisture; overloading; loose connections; external factors such as lighting, fire, flood; and design and material flaws.

The consequences of transformer failure in terms of cost can be understood from the scatter plot shown in Figure 1. Paper insulation failure has the highest frequency and cost impact, followed by design/material. Interestingly, unknown failure modes are the third largest contributor in terms of both frequency and cost. 


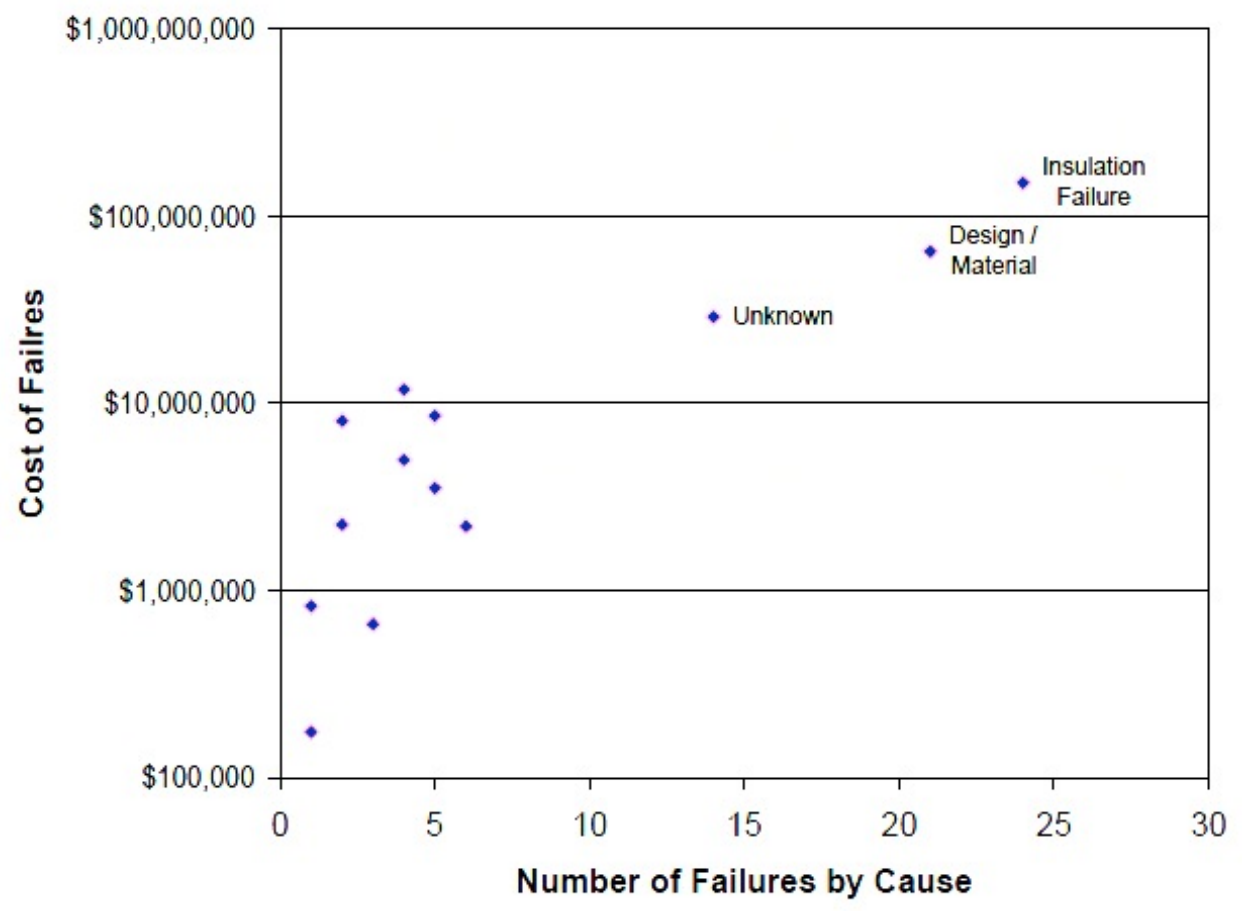

Figure 1. Frequency and severity of transformer failure in terms of cost [Bartley 2003].

\subsubsection{Paper Insulation Breakdown}

The severity of paper insulation degradation is difficult to estimate. The mechanical and dielectric strengths of the paper insulation naturally reduce with age. Two major types of transformer paper insulation are Kraft paper and pressboard. Insulation between individual windings, designed to protect against discharge between transformer coils, is made of Kraft paper. Insulation around the entire transformer coil itself is usually made of pressboard.

Many factors contribute to paper insulation degradation that may eventually lead to its failure. These include but are not limited to: heat, oxidation, acidity, moisture, mechanical forces, voltage stressing, and bubble formation [Bartley 2003; EPRI 2007]. Paper insulation is subjected to thermal stress because of heat induced by the current carried through the winding and to chemical stress because of reactions occurring within the material. These mechanisms reduce the material and dielectric strengths of the paper insulation, subsequently weakening the overall health of the winding to an extent that a fault can cause failure.

\subsubsection{Oil Contamination}

In oil-filled transformers, oil contamination is another aging and degradation concern. The two major causes for oil contamination are humidity/moisture and particles/contamination. Moisture in oil can lead to bubble formation during operation. These bubbles cause oxidation and reduce the dielectric strength of the oil. Dirt and other particle contaminants can also collect in the insulating oil, thereby decreasing the dielectric strength of the oil and forming sludge in the tank. Additionally, because of other electrical and thermal discharges occurring inside the transformer, the hydrocarbon molecules of the oil decompose, further reducing the dielectric strength of the oil. By measuring the levels of specific gases, other types of internal degradation can be identified. 


\subsubsection{Moisture}

Increased moisture in the oil tank is an indication that the seal between the high voltage terminal and the bushing cap is compromised, allowing leakage between the fitting and the roof. Assessing the moisture content in the oil should also take into consideration the moisture content in the insulation paper. This assessment is usually deduced from a moisture equilibrium chart.

\subsubsection{Overloading}

Overloading represents a condition in which a transformer is subjected to higher-than nameplate specified load for extended periods of time. This induces thermal and electric stress on the transformer, thereby degrading its health. The degradation is accelerated in aged transformers.

\subsubsection{Loose Connections}

Loose connections can be caused by the improper mating of dissimilar metals and improper torquing of bolted connections. Loose connections create thermal stress and vibration that can lead to debris in oil.

\subsubsection{External Factors}

External factors such as lighting, fire, and flood can cause catastrophic damage to transformers. These factors cannot be accounted for in the design of monitoring techniques; having lighting arrestors and good fire and flood protection systems can minimize the damage caused by these external factors.

\subsubsection{Design and Materials}

There are many factors that can arise from poor design or the use of low-quality materials, including loose or unsupported leads, loose blocking, poor brazing, inadequate core insulation, inferior short circuit strength, and foreign objects left in the tank.

\subsection{Transformer Faults Types}

To develop an online monitoring system, it is important to identify and understand fault types that might occur because of aging and degradation. In the case of transformers, fault types can be broadly classified as electrical, thermal, mechanical, and chemical fault types, as shown in Table 2.

There are different parameters associated with each fault type. An accurate diagnosis of a particular fault using measured parameters is a challenging task because of significant overlap between different fault types in the observed parameter space. In addition, lack of knowledge of the location of these faults inside the transformer makes diagnosis an even more challenging problem. 
Table 2. Fault types in transformers

\begin{tabular}{|ll|}
\hline Classification & \multicolumn{1}{|c|}{ Faults } \\
\hline Electrical & Partial discharge \\
& Arcing \\
& Static electricity \\
& Floating potential \\
& Electrical tracking \\
& Dielectric breakdown \\
\hline Mechanical & Particles in oil \\
& Insulation deterioration \\
& Core and coil vibration \\
& Oil pump bearing wear \\
& Oil and air leak \\
& Cracked LTC barrier board \\
\hline Thermal & Hot spots above $500^{\circ} \mathrm{C}$ \\
& Cellulose overheating \\
& Lightning strikes \\
& Moisture bubbling \\
& Steel rusting \\
& Water in contact with zinc coating \\
& Moisture in oil \\
& Sludge and acid formation \\
& Depolymerization of cellulose \\
\hline Chemical & \\
& \\
&
\end{tabular}

\subsection{Transformer Diagnosis Using Online Monitoring}

Online monitoring of transformers allows utilities to collect and correlate data while the transformer is in service. Utilities can use the collected data to perform predictive maintenance, diagnose incipient faults, and estimate RUL. Some of the key parameters collected from different locations within the transformer include dissolved gases in oil, moisture in oil, top oil temperature, bottom oil temperature, ambient temperature, cooling fan and pump status, load current, and tap changer information (when applicable).

Transformer oil sample analysis is a useful maintenance tool for determining transformer internal health. Along with the oil sample quality tests, performing a DGA of insulating oil is useful in evaluating transformer health [Dong 2002]. The breakdown of electrical insulating materials and components inside a transformer generates gases within the transformer. The identity of the gases being generated can be very useful information in any maintenance program; predictive maintenance is further enhanced by knowledge of the rate of gas generation. Of the several techniques used to detect gases generated inside transformers, DGA is recognized as the most informative method. DGA can be performed both online and offline.

\subsubsection{Key Gases}

All transformers generate gases to a certain extent at normal operating temperatures, but the two principal causes of gas formation within an operating transformer are electrical disturbances and thermal 
decomposition. Insulating mineral oils for transformers are a mixture of many different hydrocarbon molecules, and the decomposition process of these hydrocarbons in thermal or electrical faults is complex. The fundamental chemical reactions involve the breaking of carbon-hydrogen $(\mathrm{C}-\mathrm{H})$ and carbon-carbon $(\mathrm{C}-\mathrm{C})$ bonds. These fragments can combine with each other to form the key gases: hydrogen $\left(\mathrm{H}_{2}\right)$, methane $\left(\mathrm{CH}_{4}\right)$, acetylene $\left(\mathrm{C}_{2} \mathrm{H}_{2}\right)$, ethylene $\left(\mathrm{C}_{2} \mathrm{H}_{4}\right)$, and ethane $\left(\mathrm{C}_{2} \mathrm{H}_{6}\right)$. When cellulose insulation is involved, thermal decomposition or electric faults produce methane $\left(\mathrm{CH}_{4}\right)$, hydrogen $\left(\mathrm{H}_{2}\right)$, carbon monoxide $(\mathrm{CO})$, and carbon dioxide $\left(\mathrm{CO}_{2}\right)$. The gases generated are measured in parts per million by volume $(\mathrm{ppm} \mathrm{v} / \mathrm{v})$.

The key gases mentioned above are combustible gases. The total of all combustible gases may indicate the existence of any one or a combination of thermal, electrical, or corona faults. The primary faults associated with each of the key gases are presented in Table 3. In addition to the key gases, Oxygen $\left(\mathrm{O}_{2}\right)$ and nitrogen $\left(\mathrm{N}_{2}\right)$ are also generated, even under normal operating conditions; a low $\mathrm{O}_{2} / \mathrm{N}_{2}$ ratio indicates excessive heating inside transformer.

Table 3. Key gases and associated fault types.

\begin{tabular}{|ll|}
\hline Gas (ppm v/v) & \multicolumn{1}{c|}{ Fault (Type) } \\
\hline $\mathrm{H}_{2}$ & Partial discharge (electrical) \\
$\mathrm{CO}$ and $\mathrm{CO}_{2}$ & Cellulose degradation breakdown (thermal) \\
$\mathrm{CH}_{4}$ and $\mathrm{C}_{2} \mathrm{H}_{6}$ & Low temperature oil decomposition (thermal) \\
$\mathrm{C}_{2} \mathrm{H}_{4}$ & High temperature oil decomposition (thermal) \\
$\mathrm{C}_{2} \mathrm{H}_{2}$ & Arcing (electrical) \\
\hline
\end{tabular}

DGA can distinguish between partial discharge and arcing. Partial discharges produce mostly $\mathrm{H}_{2}$ in the oil, with very small amounts of other hydrocarbon gases and no $\mathrm{C}_{2} \mathrm{H}_{2}$. Arcing, from the largest power breakdown to the tiniest discharges, produces $\mathrm{C}_{2} \mathrm{H}_{2}$ along with hydrogen and other hydrocarbons, which can be tested as described in the American Society for Testing and Materials (ASTM) D1816 standard. As a result, the discovery of $\mathrm{C}_{2} \mathrm{H}_{2}$ is a strong indicator that arcing has taken place. Partial discharge takes place in gas bubbles or voids where voltage stress is sufficient to initiate electron avalanches and more extensive oil ionization. Prolonged corona activity in oil produces transformer wax and large amounts of hydrogen, but practically no carbon. Typical gas composition for these two types of faults is shown in Figure 2.

The characteristic composition of gases due to overheating of oil and paper, corona, and arcing are shown in Figure 3. The percentage of distribution of gases can vary depending upon the volume of oil and temperature. Therefore, establishing a nominal value of these gases for different transformer types, size, and application is a challenge. Figure 3 shows that both corona and arcing generate a large percentage of $\mathrm{H}_{2}$, but arcing results in higher percentage of acetylene generation as compared to corona.

DGA can differentiate thermal faults in oil from those in oil-impregnated paper based on the levels of hydrocarbon gases compared to carbon monoxide/dioxide. Significant production of hydrocarbon gases requires very high temperatures $\left(>400^{\circ} \mathrm{C}\right)$. The production of carbon monoxide/dioxide from paper requires only moderately elevated temperatures $\left(>150^{\circ} \mathrm{C}\right)$. The high temperatures required to thermally decompose oil result primarily from direct contact with a hot metal surface. In transformers, these conditions are typically produced by overheated joints between conductors, excessive circulating currents, and core overheating. Elevated ethylene levels and only trace amounts of acetylene are strong indicators of thermally decomposing oil. This may occur at overheated joints at the top of bushings. 


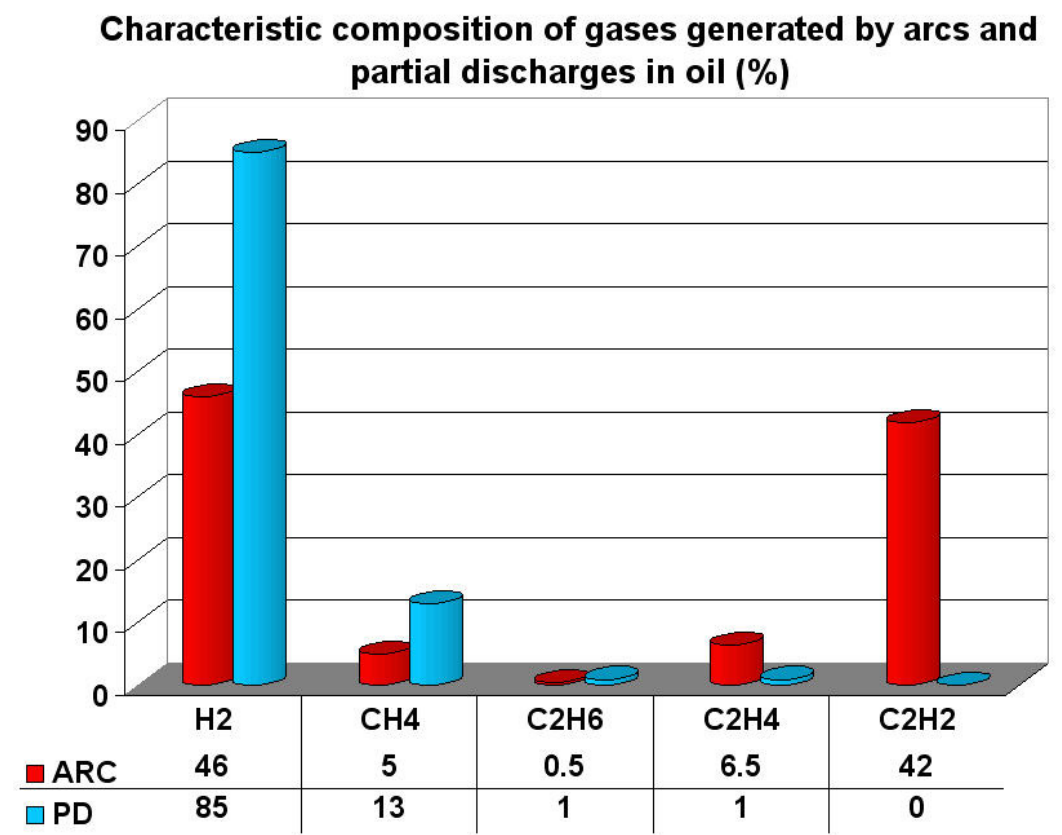

Figure 2. Gas composition for partial discharge and arcing faults [EPRI 2006b].

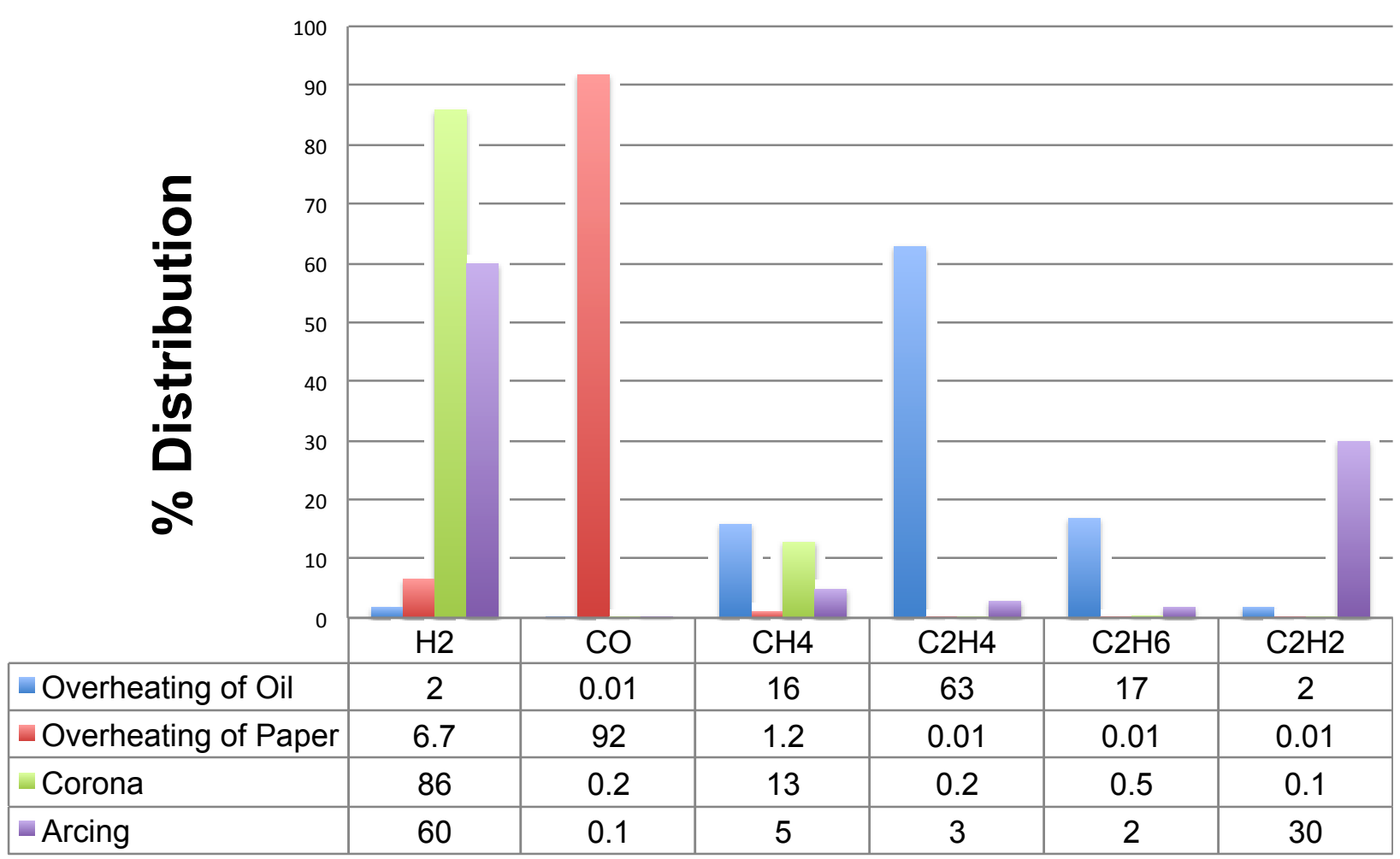

Figure 3. Characteristic composition of gases generated because of overheating of oil and paper, corona, and arcing (Morgan Schaffer Systems).

Carbon monoxide/dioxide gases result from long-term moderate (normal) heating in the bulk of the oil-impregnated cellulose, and from hot spots that develop under increased loads. DGA is unhelpful in distinguishing hot spots from bulk overheating on the basis of carbon monoxide/dioxide levels. 
Moderately heated oil-impregnated cellulose will also produce minor amounts of hydrogen, methane, ethane, and ethylene but no acetylene. Hydrocarbon gases typically come from the oil, however the additional presence of high levels of hydrogen implicates cellulose degradation.

The rate at which key gases are generated depends on the temperature and on the volume of insulation oil at that temperature. Table 4 shows the effects of temperature on key gas generation. Because of the volume effect, a large, heated volume of insulation at moderate temperature will produce the same quantity of gas as a smaller volume at a higher temperature. It is recommended that values of the key gases be trended over time so that the rate-of-change of the various gas concentrations can be evaluated. Any sharp increase in key gas concentration is an indication of a potential problem within the transformer. There are many threshold levels recommended by various organizations such as Institute of Electrical and Electronics Engineer (IEEE), International Electrotechnical Commission (IEC), Powertech Labs Inc., etc. based on the type of transformer and its operating condition.

Table 4. Gas generation at different temperature [EPRI 2006b].

\begin{tabular}{|c|c|c|c|c|c|c|c|c|c|}
\hline \multirow{2}{*}{$\begin{array}{c}\text { Paper Temperature } \\
\left({ }^{\circ} \mathrm{C}\right)\end{array}$} & \multicolumn{9}{|c|}{ Rates of gas formation from paper, in $\mathrm{ppm} /$ year $/ \mathrm{Kg}$ of paper $/ 50,0001$ of oil } \\
\hline & $\mathrm{C}_{2} \mathrm{H}_{2}$ & $\mathrm{H}_{2}$ & $\mathrm{CH}_{4}$ & $\mathrm{C}_{2} \mathrm{H}_{4}$ & $\mathrm{C}_{2} \mathrm{H}_{6}$ & $\mathrm{CO}$ & $\mathrm{CO}_{2}$ & $\mathrm{CO}_{2} / \mathrm{CO}$ & Ref. \\
\hline 125 & 0 & 0.4 & 0.3 & - & - & 4 & 220 & 50 & a \\
\hline 135 & 0 & 0.3 & 0.4 & - & - & 5 & 230 & 42 & $\mathrm{a}$ \\
\hline 160 & 0 & 40 & 12 & 3 & 3 & 122 & 1830 & 15 & $b, c$ \\
\hline $250 / 300$ & 0 & 123 & 200 & 85 & 38 & 23400 & 78000 & 3.5 & $\mathrm{a}$ \\
\hline $\begin{array}{ll}\text { a } & \text { B. Noirhomme, } \mathrm{H} \\
\text { b } & \text { M. Martins, Labelec } \\
\text { c } & \text { H. Foschum, Va Tec }\end{array}$ & Iro Queb & & & & & & & & \\
\hline
\end{tabular}

Based on the normal levels defined by IEC and Powertech Labs Inc., EPRI developed five condition diagnosis codes for transformers; for details on the condition codes, see [EPRI 2006b]. If the key gas concentration levels rapidly rise above normal levels, it is advisable to perform a confirmatory test by performing other analysis, such as gas ratio analysis.

Table 5. The values are derived from information provided within [IEEE 1978].

\begin{tabular}{|c|c|c|c|c|}
\hline & & \multicolumn{3}{|c|}{ Key Gas Concentration (ppm) } \\
\hline \multicolumn{2}{|c|}{ Gas Description } & $\begin{array}{c}\text { Normal Limit } \\
(<)\end{array}$ & $\begin{array}{c}\text { Action Limits } \\
(>)\end{array}$ & Potential Fault Type \\
\hline Hydrogen & $\mathrm{H}_{2}$ & 150 & 1000 & Corona, arcing \\
\hline Methane & $\mathrm{CH}_{4}$ & 25 & 80 & Sparking \\
\hline Acetylene & $\mathrm{C}_{2} \mathrm{H}_{2}$ & 15 & 70 & Arcing \\
\hline Ethylene & $\mathrm{C}_{2} \mathrm{H}_{4}$ & 20 & 150 & Severe overheating \\
\hline Ethane & $\mathrm{C}_{2} \mathrm{H}_{6}$ & 10 & 35 & Local overheating \\
\hline Carbon monoxide & $\mathrm{CO}$ & 500 & 1000 & Severe overheating \\
\hline Carbon dioxide & $\mathrm{CO}_{2}$ & 10,000 & 15,000 & Severe overheating \\
\hline Total Combustibles & TDCG & 720 & 4630 & \\
\hline
\end{tabular}

\subsubsection{Gas Ratios}

Note in Table 5 that if $\mathrm{C}_{2} \mathrm{H}_{4}, \mathrm{CO}$, and $\mathrm{CO}_{2}$ levels exceed the action limits, the potential fault type is severe overheating; it is not clear whether the overheating caused cellulose decomposition. Other analysis 
techniques are needed to resolve this question. Some of the most commonly used techniques include the application of IEEE C57.104-1991, Doernenburg ratios, Rogers ratios, IEC 60599, and Duval's Triangle Model [Duval 2002].

Doernenberg ratios and Rogers ratios are recognized in the ANSI/IEEE C57.104 [IEEE 1978] and are equivalent to the Basic Gas ratios in the IEC standards. The evaluation method applied for Doernenberg ratios and Rogers ratios utilizes the following gas ratios: $\mathrm{CH}_{4} / \mathrm{H}_{2}, \mathrm{C}_{2} \mathrm{H}_{2} / \mathrm{C}_{2} \mathrm{H}_{4}, \mathrm{C}_{2} \mathrm{H}_{2} / \mathrm{CH}_{4}, \mathrm{C}_{2} \mathrm{H}_{6} / \mathrm{C}_{2} \mathrm{H}_{2}$ and $\mathrm{C}_{2} \mathrm{H}_{4} / \mathrm{C}_{2} \mathrm{H}_{6}$. The use of ratios is warranted because of the varying rates of the combustible gas generation with temperature and energy variations for different fault modes. They are also warranted because gases dissolve into the mineral oil at different rates. Fault diagnosis is accomplished via a simple scheme based on ranges of the ratios. Different failure modes and associated ranges are listed in Tables 6 and 7 respectively.

The Duval Triangle method, developed by Michel Duval [Duval 2002] uses the concentration (in ppm) of methane $\left(\mathrm{CH}_{4}\right)$, ethylene $\left(\mathrm{C}_{2} \mathrm{H}_{4}\right)$, and acetylene $\left(\mathrm{C}_{2} \mathrm{H}_{2}\right)$, expressed as percentages of the total to diagnose the fault. A point (value) corresponding to the percentage of three gases are plotted on a triangular chart, which has different fault zones. The fault zone boundaries are determined empirically based on large amounts of fault data collected over 60 years. The Duval triangle chart is shown in Figure 4. The triangle coordinates are calculated as:

$\% C_{2} H_{2}=\frac{100 x}{x+y+z}$ with $x=\left[C_{2} H_{2}\right]$

$\% C_{2} H_{4}=\frac{100 y}{x+y+z}$ with $y=\left[C_{2} H_{4}\right]$

$\% C_{2} H_{4}=\frac{100 \mathrm{z}}{x+y+z}$ with $\mathrm{z}=\left[\mathrm{CH}_{4}\right]$.

Other ratios used in the diagnosis include: $\mathrm{CO}_{2} / \mathrm{CO}$ ratio; $\mathrm{O}_{2} / \mathrm{N}_{2}$ ratio; and $\mathrm{C}_{2} \mathrm{H}_{2} / \mathrm{H}_{2}$ ratio. 
Table 6. Possible fault indicators [Pamuk 2010].

\begin{tabular}{|c|c|c|}
\hline $\begin{array}{l}\text { Failure } \\
\text { Mode }\end{array}$ & $\begin{array}{l}\text { Definition of } \\
\text { Failure }\end{array}$ & Description \\
\hline PD & Partial discharge & $\begin{array}{l}\text { Gas-filled cavities are caused by inadequate impregnation, excess } \\
\text { moisture in the paper, excessive saturated oil, oil vacancy, and X-wax in } \\
\text { the cavity formed by the line conductor discharges where it occurred. }\end{array}$ \\
\hline \multirow[t]{4}{*}{ D1 } & \multirow[t]{4}{*}{$\begin{array}{l}\text { Discharge at low } \\
\text { energy }\end{array}$} & $\begin{array}{l}\text { Have different potential in a bad connection, display public, in toroid, } \\
\text { winding or conductor adjacent to the disc, broken in welding or soldering, } \\
\text { core in the closed lip and arc occurring. }\end{array}$ \\
\hline & & $\begin{array}{l}\text { Fittings, bushing-tank, high-voltage, and line-to-earth (core, tank, yoke) } \\
\text { between the discharges. }\end{array}$ \\
\hline & & $\begin{array}{l}\text { Board materials, adhesives and insulation between the windings formed } \\
\text { on the dielectric discharges occurring on roads. }\end{array}$ \\
\hline & & Oil drilling, under LTC selector switch and cutting current. \\
\hline \multirow[t]{3}{*}{ D2 } & \multirow[t]{3}{*}{$\begin{array}{l}\text { Discharge at high } \\
\text { energy }\end{array}$} & $\begin{array}{l}\text { Jumps, ways of conducting discharge, high energy and their power in } \\
\text { local arc to continue. }\end{array}$ \\
\hline & & $\begin{array}{l}\text { Low-voltage-to-ground, bushing-tank, winding-core, copper bar between } \\
\text { the tank link, coils in the oil ducts and pipes caused in short-circuit. }\end{array}$ \\
\hline & & $\begin{array}{l}\text { Insulation between conductors, core insulation of the screws holding the } \\
\text { arm and the core of the metal ring around the magnetic fluxes occurrence. }\end{array}$ \\
\hline \multirow[t]{3}{*}{$\mathrm{T} 1$} & \multirow{3}{*}{$\begin{array}{l}\text { Thermal faults } \mathrm{T} \\
<300^{\circ} \mathrm{C}\end{array}$} & The work overload of the transformer in case of emergency. \\
\hline & & Flux between the windings and oil reduction of blockages. \\
\hline & & The uneven pressure iron yoke leakage flux. \\
\hline \multirow[t]{3}{*}{$\mathrm{T} 2$} & \multirow[t]{3}{*}{$\begin{array}{l}\text { Thermal faults } \\
300<\mathrm{T}<700^{\circ} \mathrm{C}\end{array}$} & $\begin{array}{l}\text { Selector switch positions in the bolted connections between the contacts } \\
\text { are damaged badly in contact, the contact shifts in the carbon formation, } \\
\text { bad contacts in the cable and bushing connection. }\end{array}$ \\
\hline & & $\begin{array}{l}\text { Connection between the yoke and bolts and connections between the hair, } \\
\text { grounding wire, the magnetic screen or in the worst sources connection } \\
\text { (in print) caused by circulating currents. }\end{array}$ \\
\hline & & $\begin{array}{l}\text { Side-by-side between the windings of the parallel conductors in the } \\
\text { insulating material wears. }\end{array}$ \\
\hline \multirow[t]{3}{*}{ T3 } & \multirow{3}{*}{$\begin{array}{l}\text { Thermal faults } \mathrm{T} \\
>700^{\circ} \mathrm{C}\end{array}$} & Tank and a large circulating current in the core. \\
\hline & & $\begin{array}{l}\text { Unbalanced high magnetic fields, a smaller tank that was caused by } \\
\text { currents in the wall. }\end{array}$ \\
\hline & & Short circuits that occur in the core. \\
\hline
\end{tabular}

\subsection{3 $\quad \mathrm{CO}_{2} / \mathrm{CO}$ Ratio}

The ratio of $\mathrm{CO}_{2} / \mathrm{CO}$ is sometimes used as an indicator of the thermal decomposition of cellulose. The rate of generation of $\mathrm{CO}_{2}$ typically runs 7 to 20 times higher than $\mathrm{CO}$. It is therefore considered normal if the $\mathrm{CO}_{2} / \mathrm{CO}$ ratio is above 7. $\mathrm{A} \mathrm{CO}_{2} / \mathrm{CO}$ ratio less than 5 is indicative of a problem. If cellulose degradation is the problem, $\mathrm{CO}, \mathrm{H}_{2}, \mathrm{CH}_{4}$, and $\mathrm{C}_{2} \mathrm{H}_{6}$ will also be increasing significantly. At this point, it is recommended that additional furan testing be performed. If the $\mathrm{CO}_{2} / \mathrm{CO}$ ratio is 3 or under with increased furans, severe and rapid deterioration of cellulose is occurring and consideration should be given for taking the transformer out of service for further inspection. 
Table 7. Ranges for Doernenberg and Rogers ratios [Hamrick 2010].

\begin{tabular}{|c|c|c|c|c|c|c|}
\hline & \multicolumn{5}{|c|}{ Fault Type } \\
\hline & & $\mathrm{T} 1$ & $\mathrm{~T} 2$ & T3 & D1 & D2 \\
\hline \multirow[t]{3}{*}{ Ratio Description } & Gas Ratio & Thermal Fault & Thermal & Thermal & Low & High \\
\hline & & $<300^{\circ} \mathrm{C}$ & Fault & Fault & Energy & Energy \\
\hline & & & $300-700^{\circ} \mathrm{C}$ & $>700^{\circ} \mathrm{C}$ & Discharge & Discharge \\
\hline \multicolumn{7}{|l|}{ Doernenberg Ratios } \\
\hline R1 - Methane/Hydrogen & $\mathrm{CH}_{4} / \mathrm{H}_{2}$ & & $1.0<\mathrm{R} 1$ & & $\mathrm{R} 1<0.1$ & $0.1<\mathrm{R} 1<1.0$ \\
\hline R2 - Acetylene/Ethylene & $\mathrm{C}_{2} \mathrm{H}_{2} / \mathrm{C}_{2} \mathrm{H}_{4}$ & & $\mathrm{R} 2<.75$ & & $\mathrm{R} 3<0.3$ & $0.75<\mathrm{R} 2$ \\
\hline R3 - Acetylene/Methane & $\mathrm{C}_{2} \mathrm{H}_{2} / \mathrm{CH}_{4}$ & & $\mathrm{R} 3<0.3$ & & $0.4<\mathrm{R} 4$ & $0.3<\mathrm{R} 3$ \\
\hline R4-Ethane/Acetylene & $\mathrm{C}_{2} \mathrm{H}_{6} / \mathrm{C}_{2} \mathrm{H}_{2}$ & & $\mathrm{R} 4<0.4$ & & & $\mathrm{R} 4<0.4$ \\
\hline \multicolumn{7}{|l|}{ Rogers Ratios } \\
\hline R1 - Methane/Hydrogen & $\mathrm{CH}_{4} / \mathrm{H}_{2}$ & $1.0<\mathrm{R} 1$ & $1.0<\mathrm{R} 1$ & $<\mathrm{R} 1$ & $\mathrm{R} 1<0.1$ & $0.1<\mathrm{R} 1<1.0$ \\
\hline R2 - Acetylene/Ethylene & $\mathrm{C}_{2} \mathrm{H}_{2} / \mathrm{C}_{2} \mathrm{H}_{4}$ & $\mathrm{R} 2<0.1$ & $\mathrm{R} 2<0.1$ & $\mathrm{R} 2<0.1$ & $\mathrm{R} 2<0.1$ & $1.0<\mathrm{R} 2<3.0$ \\
\hline R5 - Ethylene/Ethane & $\mathrm{C}_{2} \mathrm{H}_{4} / \mathrm{C}_{2} \mathrm{H}_{6}$ & $1.0<\mathrm{R} 5<3.0$ & $1.0<\mathrm{R} 5<3.0$ & $3.0<\mathrm{R} 5$ & $\mathrm{R} 5<1.0$ & $3.0<\mathrm{R} 5$ \\
\hline
\end{tabular}

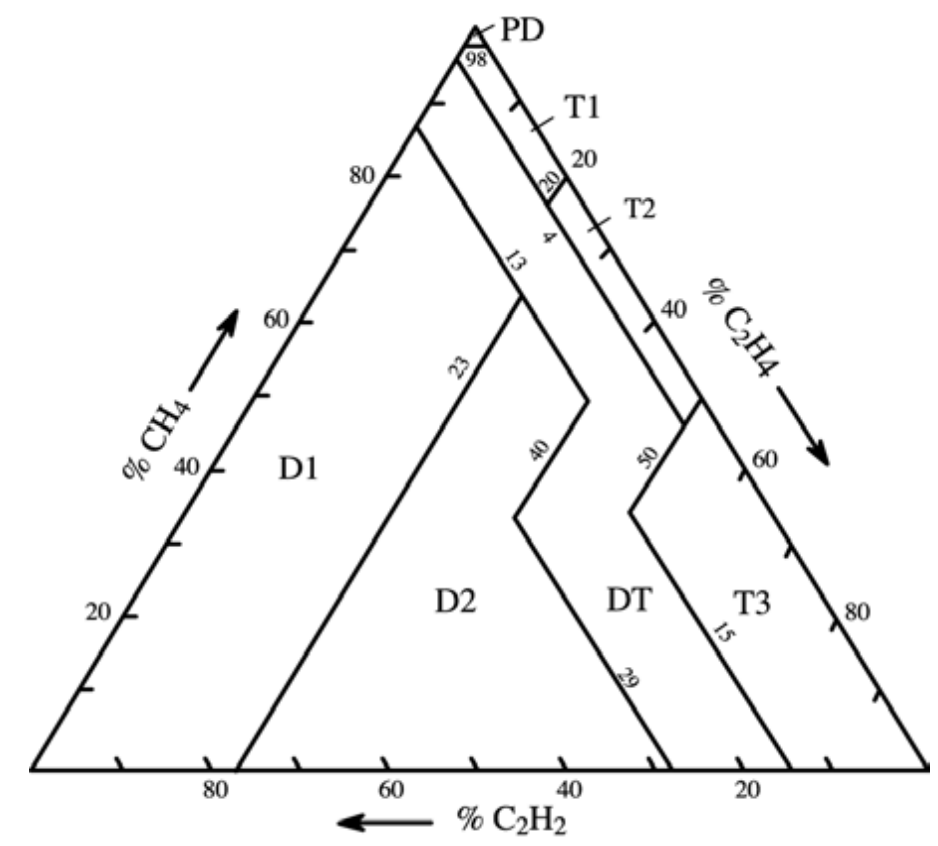

Figure 4. Duval triangle chart [Duval 2002].

\subsection{4 $\mathrm{O}_{2} / \mathrm{N}_{2}$ Ratio}

During the breakdown of $\mathrm{C}-\mathrm{H}$ and $\mathrm{C}-\mathrm{C}$ bonds to form key gases, nitrogen and oxygen gases are also generated but are not used individually as the guide gases for fault diagnosis. Excessive pressure in the system provides useful information on leaks and temperature changes. Oxygen is the gas responsible for the deterioration of cellulose material and the oil, hence oxygen level needs to be as low as possible. The rapid decline of oxygen levels indicates changing oil properties; the formation of other gases indicates overheating. Temperature changes in gas-insulated systems affect the amount of nitrogen. When the insulation oil is heated and cooled, the nitrogen gas pressure fluctuates. These fluctuations change the concentration of nitrogen relative to other gases. The $\mathrm{O}_{2} / \mathrm{N}_{2}$ ratio in healthy transformers should be near 0.5 . When this ratio falls below 0.3 , the insulating oil is subjected to oxidation. 


\subsection{5 $\quad \mathrm{C}_{2} \mathrm{H}_{2} / \mathrm{H}_{2}$ Ratio}

The operation of tap changers creates low-energy discharges, resulting in gas formation. As the $\mathrm{C}_{2} \mathrm{H}_{2} / \mathrm{H}_{2}$ ratio in the main tank approaches a threshold limit, it indicates that the level tank pollutes the main tank. However, the $\mathrm{C}_{2} \mathrm{H}_{2} / \mathrm{H}_{2}$ rate and the amount of acetylene formed are dependent on the number of tap changer operation, and the contamination level depends on the size of the main transformer.

Water in the electrical equipment should always be maintained at the lowest possible level. Water found in a free state (dissolved in oil or insulating paper) always has a negative impact on the equipment. Hydrated cellulose materials are subjected to corona. Increased water temperature yields higher levels of hydrogen in the core, causing the release of air and leading to unwanted electrolysis events.

When cellulose insulation decomposes because of overheating, furanic compounds are released and dissolved into the oil, along with $\mathrm{CO}$ and $\mathrm{CO}_{2}$. In healthy transformers, there are no detectable furans in the oil $(<100 \mathrm{ppb})$. As the cellulose degrades, the furan levels will increase. Furan levels of 500-1000 ppb are indicative of accelerated cellulose aging, with furan levels $>1500 \mathrm{ppb}$ indicating a high risk of insulation failure.

\subsection{Deenergized Transformer Testing}

NPPs perform routine maintenance and testing of deenergized transformers, often during plant outages. This work includes: power factor testing, infrared testing, transformer turn ratio testing, oil moisture testing, interfacial tension (IFT) testing, dielectric breakdown testing, and degree of polymerization (DP) testing.

Power factor testing, also known as doble testing, is an effective way to detect defective electrical equipment insulation, contaminants, and, to an extent, moisture in the transformer winding. The power factor is the ratio of the capacitive or charging current to resistive or leakage current. Power factor values close to unity are preferred.

Infrared testing is used to identify hot spots both inside and outside a transformer, and can also be used to check the effectiveness of the cooling system.

Transformer turn ratio testing is performed to detect impending breakdown in windings or insulation. The direct correlation between numbers of turns (both primary and secondary side) to the voltage is used to deduce the breakdown. The extent of voltage deviation from nameplate values is a direct indication of winding degradation.

Oil testing involves collecting oil samples and then sending the samples for laboratory testing to measure the dissolved gas concentration (this is equivalent to offline DGA). Oil sampling enables maintenance personnel to deduce moisture level, IFT, and dielectric breakdown. An increase in oil contamination and moisture level reduces the IFT. The color of the collected oil sample is also often a good indication of the dielectric strength of the oil.

The DP test is another means for assessing insulation aging. This test is performed on paper samples. The DP test provides an estimate of the average polymer size of the cellulose molecules in materials such as paper and pressboard. Paper in new transformers generally has a DP near 1000. Aged paper with a DP of 150 to 200 has little remaining mechanical strength, and therefore makes windings more susceptible to mechanical damage during movement, particularly during extreme events such as through-faults. As insulation aging in transformers can be uneven because of thermal, moisture, oxygen, and byproduct concentration, gradients samples from various locations are needed to provide the best diagnosis of the overall insulation condition. 


\subsection{Diagnostic Techniques for Fault Classification}

Paper insulation failure is the most common and frequent type of failure. The primary cause of paper insulation degradation is electrical discharge - partial discharge and arcing. DGA is one of the most effective tools to detect electrical discharges, hot spots, and other types of faults inside transformers by measuring the level of dissolved gases. Saha [2003] provides a review of techniques used to diagnose the condition of insulation in aging transformers using DGA. Statistical learning techniques can be used to classify these faults and assess the condition of transformers. Shintemirov et al. [2009] used a bootstrapping technique to resample faulty samples and extract classification features using genetic programming. The resulting features were used as the inputs to artificial neural network, support vector machines, and $K$-nearest neighbors $(K-\mathrm{NN})$ classifiers to perform multiclass fault identification. Ma et al. [2012] use DGA and polarization/depolarization current (PDC) information independently and in combination to extract features that are used as an input to support vector machines. PDC information can also be used to assess the paper insulation condition in transformers [Bhumiwat 2004]. DGA is also used to assess condition of oil filled bushing [EPRI 2006b]. Lin et al. [1993] developed an expert system based on fuzzy set concept to diagnose faults in transformers.

One of the limitations of DGA is its inability to deduce the location of electrical discharge inside the transformer. Therefore, there has been a wide interest in developing sensors that can be placed inside transformers to monitor dissolved gases and use acoustic waves to identify the location of discharges. An electric discharge results in the generation of acoustic waves.

EPRI, in collaboration with The Center for Photonics Technology at Virginia Tech, has developed an acoustic fiber-optic sensor intended for locating and detecting electrical discharge (partial discharge in particular) based on acoustic emission (AE) [EPRI 2005; EPRI 2007]. Fiber-optic sensors made from dielectric materials, such as fused-silica glass and sapphire, are inherently immune to electromagnetic interference. Based on the AE data collected from different transformer locations, the NOESIS ${ }^{\circledR}$ software was developed based on the Learning Vector Quantizer, a Kohonen unsupervised neural network [EPRI 2005, EPRI 2007]. The Learning Vector Quantizer classifier was trained on a data set collected from a gassing unit.

EPRI also developed a sensor highway system that combined AE and vibration signals for fault diagnosis in LTCs [EPRI 2006a]. EPRI, in collaboration with The Center for Photonics Technology, has also developed fiber-optic sensors to measure hydrogen and acetylene concentration [EPRI 2006a].

Judd et al. [2004] showed that ultra-high frequency (UHF) monitoring can be used to isolate partial discharge arcing; at least three sensors are required to determine the actual location of the partial discharge arcing. UHF sensors may be mounted external to the transformer through dielectric windows, which would be straight forward to install during manufacturing and may be possible to retrofit to existing transformers in service [Judd et al. 2004]. One drawback of UHF testing is the shear amount of data that is generated [Catterson 2008]. In addition to detecting partial discharge, UHF sensors can be used for active interrogation of the mechanical structure to detect displacement. After potentially damaging events, such as through faults, harsh loading, or physical deformation, the same UHF sensors installed for partial discharge monitoring could be used to determine if the internal structure of the transformer has been permanently altered or has returned to its original state [Judd 2004].

Utilization of different monitoring techniques, different forms of information, and knowledge about transformer current age and operating condition will enable maintenance personnel to perform predictive diagnosis and prognosis.

\subsection{Transformer Prognosis}

There has been a wide interest across different industries to accurately estimate the RUL of transformers, especially GSUs. Accurately estimating RUL would reduce maintenance cost and prevent 
unplanned outages, which are highly undesirable because they are the key links between the power generating station and the transmission grid.

An accurate estimation of transformer RUL is affected by a number of operating factors, including transformer load, ambient temperature, moisture in the oil, oxygen content in the oil, oil level, the condition of the cooling system, and oil contamination. Many studies have observed that an estimate of transformer insulation RUL is sufficient to estimate the transformer RUL, as paper insulation failure, the most frequent failure mode for transformers, can be catastrophic [Muthanna 2006; Pradhan 2005].

Muthanna et al. [2006] simulated and modeled the time of failure of the insulation of GSUs given the operating history of the transformer. The simulation to predict the transformer insulation life took into consideration the actual load variations per hour, ambient temperature, and average load variation per year. The IEEE Life model was used to model the thermal aging of insulation and to predict the transformer insulation life. An alternative approach to predict transformer insulation life based on statistical renewal theory was proposed. Interesting reliability metrics were calculated using renewal theory, including time taken to consume $\mathrm{x} \%$ of design life and the probability of lasting $\mathrm{X}$ years.

Pradhan et al. [2005] developed a semiempirical expression to estimate the loss of life in transformers by analyzing the gas content and the concentration of furfural dissolved in the insulating oil. Hong et al. [2009] applied standard statistical techniques to the left-truncated, right-censored transformer lifetime data for transformers in service from 1980 to 2008. The authors divide transformers into old and new transformers (transformers put into service prior to and after 1987) to account for the shift in transformer reliability during this time.

Coble et al. [2011] and Strong et al. [2011] simulated ambient temperature, DP, water contamination in paper insulation, furan concentration, winding temperature, and oil contamination. Different prognostic techniques, including general path models, neural networks, and kernel regression, were used to estimate the RUL of transformer based on simulated data. 


\section{FW-PHM SOFTWARE SUITE}

The FW-PHM is an integrated suite of Web-based diagnostic and prognostic tools and databases, developed for EPRI by Expert Microsystems, specifically designed for use in the commercial power industry (both nuclear and fuel). FW-PHM serves as an integrated health management framework, as shown in Figure 5, managing the functionality needed for a complete implementation of diagnostics and prognostics [Lybeck 2011]. As part of this pilot project, INL is beta-testing the software, along with other EPRI members.

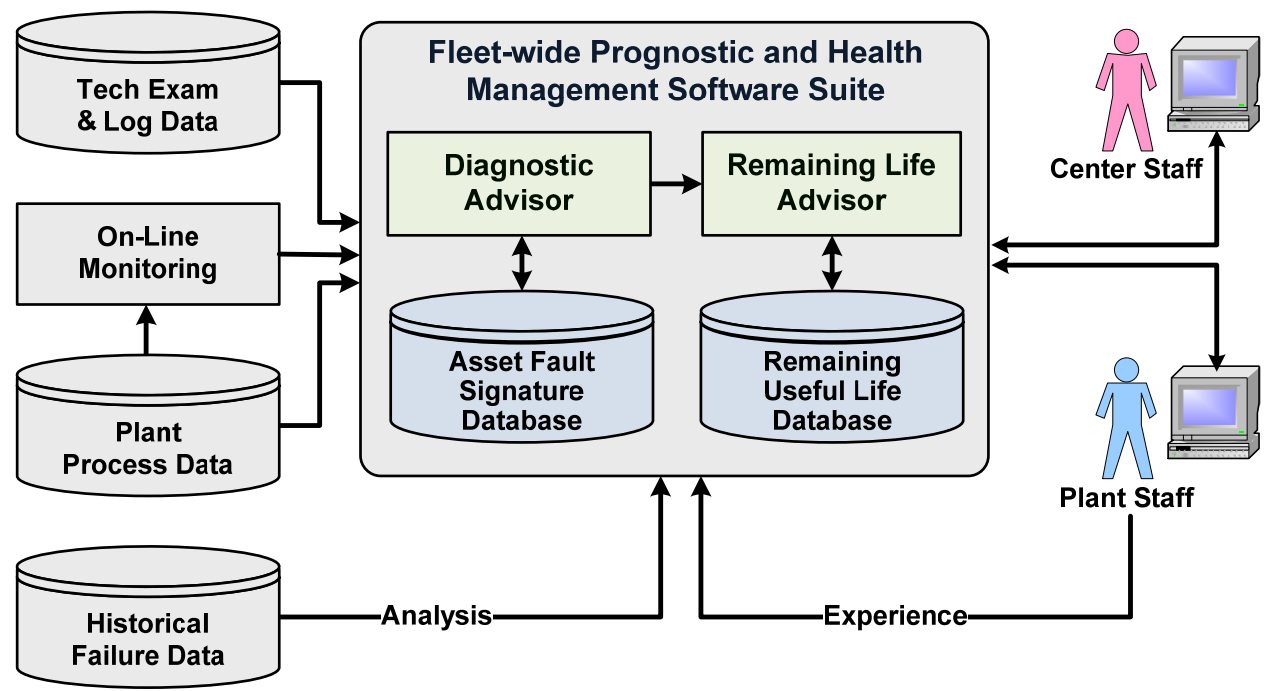

Figure 5. Data flow in the EPRI software suite [EPRI 2011b].

\subsection{Software Description}

FW-PHM is built with an open architecture, and is based on a reference database of power industry asset types, fault types, and technology examination types. There are four modules that provide the key functionality of the software. The Diagnostic Advisor identifies impending failures by comparing fault signatures with operating data. The AFS Database organizes fault signatures collected across the industry. The Remaining Life Advisor estimates how long an aging or faulty asset will continue to provide reliable service. The Remaining Useful Life Database organizes asset RUL models collected across the industry. EPRI Report [EPRI 2011b] includes a product summary.

The software suite is designed to run on both 32-bit and 64-bit versions of Windows Server 2003, Windows Server 2008, and Windows 7 Operating Systems. The Web Client is designed to run from Internet Explorer 6, 7, and 8 on any windows operating system newer than Windows XP Service Pack 3.

Each implementation of the FW-PHM consists of the EPRI master database and a local userdeveloped database. Users may choose to periodically export their databases for inclusion in the EPRI database as shown in Figure 6. EPRI will evaluate new information for inclusion in the master database, and periodically publish updates to the master database. 


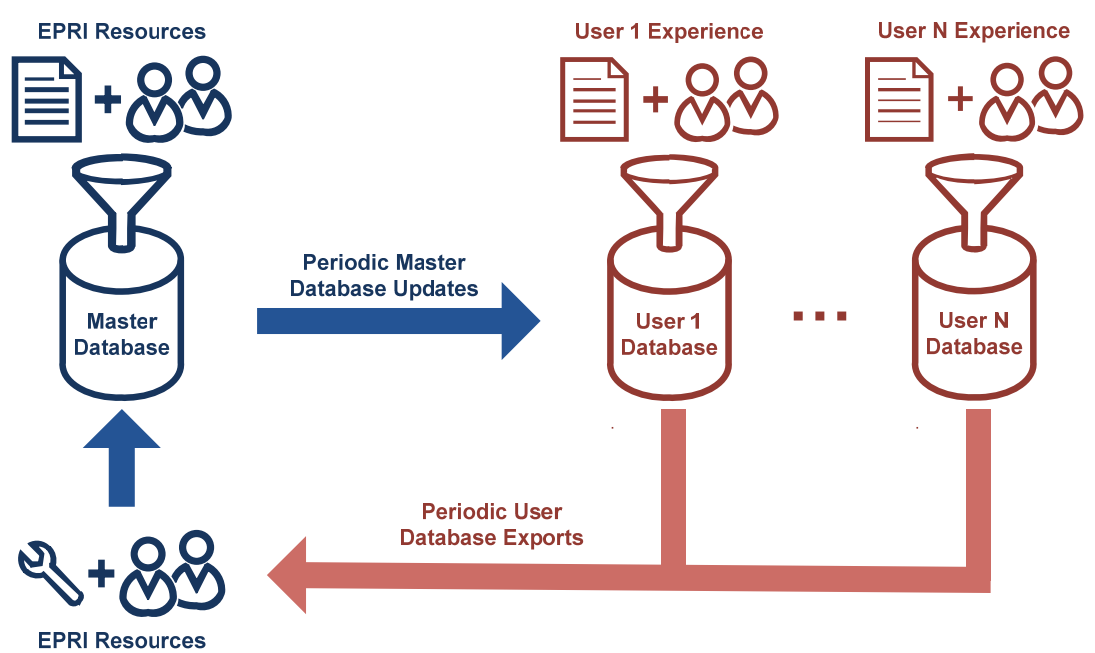

Figure 6. EPRI master database and user local database aggregation and periodic master database updates [EPRI 2011b]. 


\section{BETA TESTING APPROACH}

Beta testing is currently in progress. The information presented here describes the general approach to beta testing; full results will be presented to EPRI at the conclusion of testing. Beta testing will encompass installation and configuration, content-based testing, data synchronization, and a human factors usability analysis.

\subsection{Installation and Configuration}

The software has been installed and configured for use at INL. All components were installed on a single Virtual Machine with a Windows Server 2008 R2 Operating System. The database technology deployed was Oracle 11g. The software has been configured for multiple users.

\subsection{Content-Based Testing}

The primary goal of beta-testing at INL is content-based testing. Tests will be based on the GSU Transformer and the EDG systems. Based on research and input from industry, several fault modes of interest will be identified and entered into the AFS database, along with the associated fault signatures. Appropriate technical examinations will then be defined and entered into the database. Test scenarios will be developed and implemented to evaluate and document the ability of the software to offer the most appropriate diagnosis (or diagnoses) for an incomplete set of symptoms.

Additionally, a real-life prognostic model (not necessarily directly applicable to the GSU Transformer or the EDGs) will be implemented in the RUL database. The model will be implemented using several test scenarios in the RUL advisor to ensure correct implementation and functionality.

\subsection{Data Synchronization}

INL has already tested the procedure to install an updated version of the master EPRI database. As part of continued testing, the INL local database will be exported and sent to EPRI to evaluate the data synchronization process.

\subsection{Human Factors Usability Analysis}

Usability can be defined as the science of making technology work for people. Analyzing novel software applications from a Human Factors perspective significantly contributes to a user-centered or user-friendly design - a design that meets the goals, needs, and limitations of the software user. Failing to focus on the user early in the design process is a critical and common error with Human Factors professionals brought in at the eleventh hour to provide a detailed usability review or sign off on a finished product. Increased attention to the user from the beginning contributes significantly to a better product in terms of cost and efficiency. Indeed, rich functionality is worth little if it cannot be accessed by the very user for which it is intended [Human Factors International].

A Human Factors usability analysis examines a number of features relating to software applications. Among these are: learnability, ease of use, accessibility, intuitiveness, efficiency, simplicity, and consistency. These seven aspects of usability will be employed to evaluate the EPRI On-Line Monitoring software application.

\subsubsection{Learnability}

Learnability refers to the ease by which a user learns to use a software interface.

\subsubsection{Ease of Use}

Ease of Use refers to the ease by which a user manipulates controls or displays within the software interface. 


\subsubsection{Accessibility}

Accessibility focuses on a number of navigation tools within an interface. The speed by which a site loads may significantly affect a user's perception of the software. Waiting extended periods of time for the site to load creates impatience in the user, which may lead to resistance in using the tool. Main menu navigation is another critical component of an accessible user interface. Forcing the user to rely on back and forward arrows or clicking to "x out" of a page to return to the Main Menu may increase frustration levels and reduce levels of patience in users. Rather, a prominent icon displayed consistently throughout the interface allows the user to return time and again to the Main Menu, saving time and increasing accessibility. It is critical that an interface feature a prominent site search tool as well as a prominent help tool. It is best that each be represented by easily identifiable icons commonly used to represent these tools, such as a magnifying glass or search box for the search tool and a question mark for the help tool.

\subsubsection{Intuitiveness}

Intuitiveness refers to information provided to the user when accessing the software interface. Users may ask two questions of the interface: Does the technology do what the user expects it to do? Does the technology provide enough information to indicate the functions it provides?

\subsubsection{Efficiency}

Efficiency refers to the means by which the user learns the interface and how quickly thereafter the user can carry out the tasks intended.

\subsubsection{Simplicity}

A well known design principle acronym coined by Lockheed Engineer Kelly Johnson is KISS (keep it simple stupid). The KISS principle states that most systems work best if the key goal is simplicity, eschewing complexity at every opportunity. Example of KISS would be adherence to a favorable, yet simple approach to text/ background contrasts. Despite the multitude of options available, the merits of a classic black font on a white background cannot be disputed. This display reduces visual clutter and enhances readability.

\subsubsection{Consistency}

Along with the merits of simplicity, consistency throughout an interface is critical to a well-designed software interface. Consistent layouts, headings, style, and color throughout link the contents of the interface and add to the overall effect while too many font styles, sizes, graphics, and colors create a chaotic, choppy effect. 


\section{DIAGNOSTIC PATHWAY SPECIFICATIONS FOR GSUs}

The steps followed in EPRI [2012] to develop diagnostic fault signature information for large motor driven pumps are also followed here to develop fault signature information for GSUs. A diagnostic fault signature for GSUs is elicited from Shearon Harris Nuclear Generating Station experts and stored in the AFS database. As defined in [EPRI 2012], a fault signature is a structured representation of the information that an expert would use to first detect and then verify the occurrence of a specific type of fault. A fault describes a particular mode of degradation that can be detected by analysis of plant information before the asset condition reaches the point of failure to meet a service requirement. Implied is an assumption that the fault is detectable by analysis of plant information and that the analysis can be performed in time to prevent or otherwise remedy the fault condition before it becomes a failure condition.

A fault signature has three information attributes: Asset Type; Fault Type; and Fault Features, as shown in Figure 7. The steps followed to populate the AFS database with different fault signatures are shown in Figure 8.

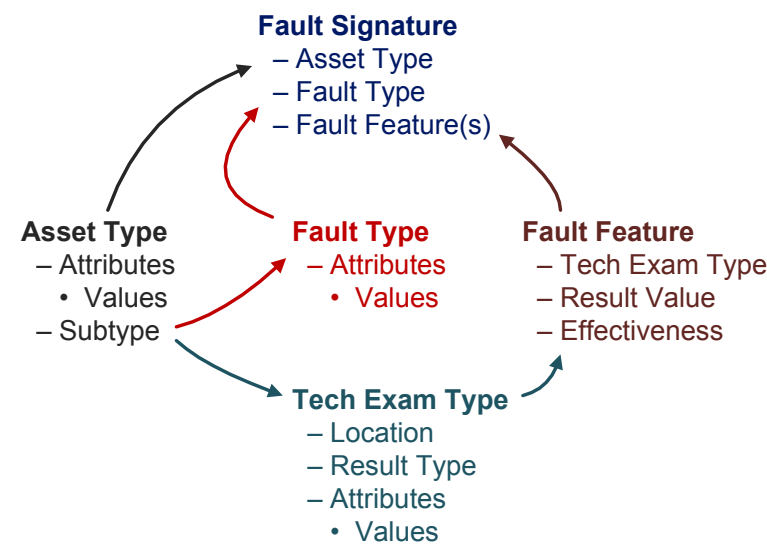

Figure 7. Different Attributes of fault signature [EPRI 2012].

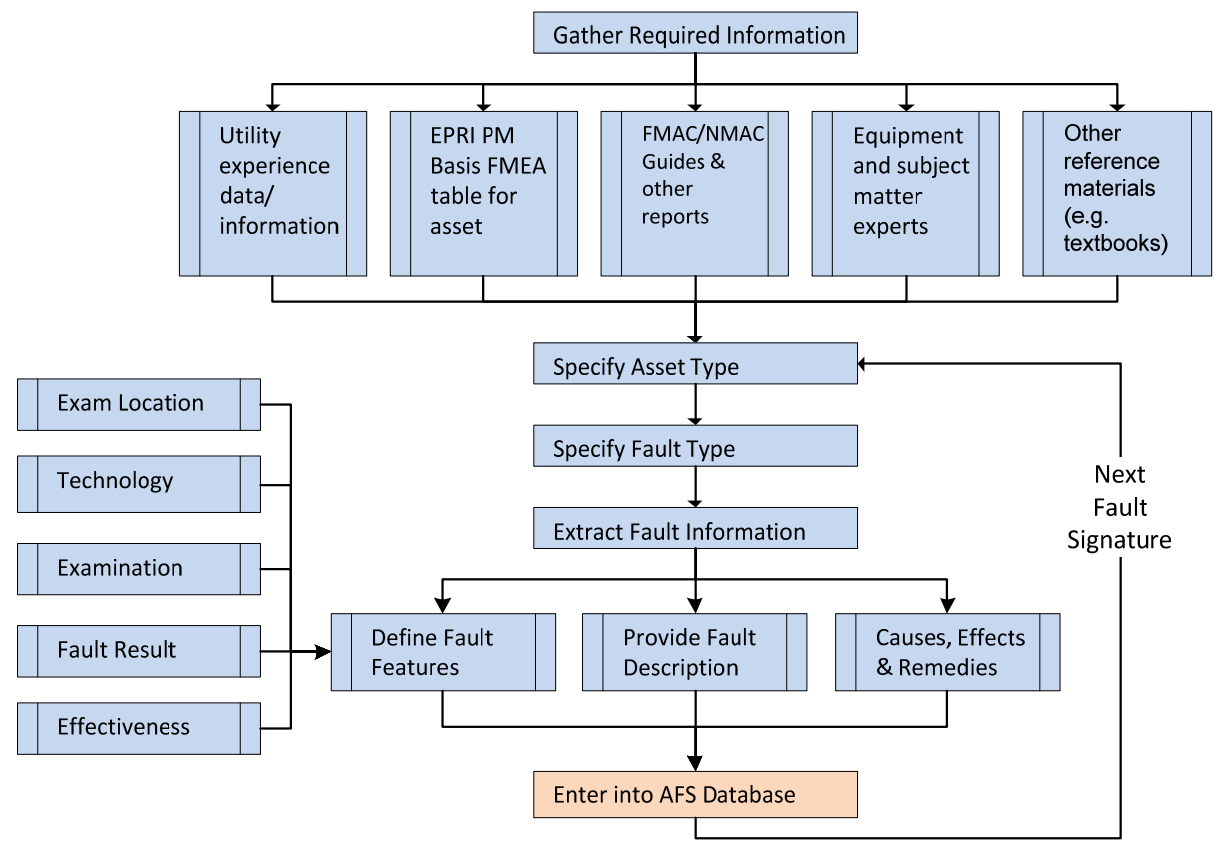

Figure 8. Steps involved in gathering fault signature [EPRI 2012]. 


\subsection{Asset Type Definition}

Diagnostic fault signature information will often be uniquely applicable to a specific type of asset. Although fault signatures are developed and organized with reference to a specific type of asset, it is desirable to specify fault signatures to apply as broadly as possible. The fault signatures detailed in this section are defined with reference to a particular configuration of a GSU transformer used in a nuclear plant service environment. However, many of the fault signatures defined in this section might be applied to similar assets used in similar service environments. The applicability of the following fault signatures is limited to:

- Plant Types: Nuclear steam type

- Unit Types: Pressurized water reactor

- System Types: Electrical system

- Equipment Type: GSUs

- Component Types: Winding insulation, insulation oil, LTCs, bushings, cooling fans, pumps

\subsection{Fault Type Definition}

Objectives for the initial meeting with Duke Energy Progress were to elicit several diagnostic fault signatures for GSU transformers; this knowledge will subsequently be captured in the AFS database. The failure modes addressed during the meeting are listed in Table 8. Each failure mode listed in Table 8 can result from one or more fault conditions progressing to the listed failure condition. A primary purpose of this document is to capture and report the results of an elicitation of diagnostic signatures for the primary types of faults known to progress to these failure modes in GSUs.

Table 8. Failure modes and contributing fault types considered.

\begin{tabular}{|ll|}
\hline Failure Mode & Contributing Fault Types \\
\hline Insulating Oil Breakdown & Loss of dielectric strength of insulating oil \\
Insulating Oil Acidity & $\begin{array}{l}\text { Acidity level of the insulating oil } \\
\text { Water ingress in the insulating oil } \\
\text { Thermal degradation of winding insulation }\end{array}$ \\
Insulating Oil Contaminated & Particulate contamination of oil \\
Winding Insulation Degradation & $\begin{array}{l}\text { Loss of dielectric strength of winding insulation } \\
\text { Damage of winding insulation while maintenance activity } \\
\text { Water ingress into the oil }\end{array}$ \\
& $\begin{array}{l}\text { History of operation at high temperature for sustained period } \\
\text { Bladder tank leak in the conservator }\end{array}$ \\
Bushing Degradation & $\begin{array}{l}\text { Loss of bushing dielectric strength } \\
\text { Water ingress in the bushing }\end{array}$ \\
Cooling System Failure & Oil pump motor performance \\
& $\begin{array}{l}\text { Loss of electric power } \\
\text { Bad breaker } \\
\text { Oil pump fan }\end{array}$ \\
\hline
\end{tabular}




\subsection{Fault Feature Definition}

A fault feature describes a characteristic of plant information that can be used to detect and verify that a specific type of fault is occurring. Determining the presence of a fault feature typically involves an analysis of plant data. For example, plant data might include a temperature reading of $100^{\circ} \mathrm{C}$ and an analysis of that data might determine that the data is Low, Normal, or High in the operating context of the asset. A fault feature might then be expressed by stating that a High value of this particular type of temperature measurement is an indicator that a particular fault type is occurring for the asset associated with the temperature measurement. Data analysis can be used to determine the thresholds for Normal or Abnormal; abnormal values can be low or high depending on the type of data.

The fault features listed in Table 9. are used to diagnose the fault types considered for the failure modes listed in Table 8.

Table 9. Summary of fault features used to diagnose fault types considered.

\begin{tabular}{|c|c|c|}
\hline Feature Type & Location & Possible Values \\
\hline Inspection: Oil Level & Main Oil Tank & $\begin{array}{l}\text { Normal } \\
\text { Low }\end{array}$ \\
\hline Inspection: Top Oil Temperature & Main Oil Tank & $\begin{array}{l}\text { Normal } \\
\text { Marginal } \\
\text { High }\end{array}$ \\
\hline DGA: Oil Moisture & Main Oil Tank & $\begin{array}{l}\text { Normal } \\
\text { Abnormal }\end{array}$ \\
\hline DGA: Oil Gas & Main Oil Tank & $\begin{array}{l}\text { Normal } \\
\text { Marginal } \\
\text { High }\end{array}$ \\
\hline Oil Analysis: Particle Count & Main Oil Tank & $\begin{array}{l}\text { Normal } \\
\text { Abnormal }\end{array}$ \\
\hline Maintenance Action: Oil Replacement & Insulating oil supply: Reservoir & $\begin{array}{l}\text { Normal } \\
\text { Recent } \\
\text { Very Recent }\end{array}$ \\
\hline Inspection: Oil Color Change & Main Oil Tank & $\begin{array}{l}\text { Normal } \\
\text { Abnormal }\end{array}$ \\
\hline Loss of dielectric strength & Insulation Winding & \\
\hline Oil Analysis: Interfacial Tension & Main Oil Tank & $\begin{array}{l}\text { Normal } \\
\text { Abnormal }\end{array}$ \\
\hline Doble Analysis: Doble Capacitance & Bushing & $\begin{array}{l}\text { Normal } \\
\text { Abnormal }\end{array}$ \\
\hline
\end{tabular}




\begin{tabular}{|lll|}
\hline Feature Type & Location & Possible Values \\
\hline & & \\
Current Transformer: Motor Current & Motor Lead Current Probe & $\begin{array}{l}\text { Normal } \\
\text { Abnormal }\end{array}$ \\
& & Normal \\
Megger Inspection: Motor Insulation Resistance & Pump Motor & Abnormal (low) \\
& Fan Motor & Normal \\
Power Transformer Potential: Motor Ground & Motor Control Center & Abnormal \\
Potential & & Normal \\
& & Abnormal \\
Doble: Sweep Frequency Response & Main Oil Tank & \\
\hline
\end{tabular}

Preliminary specifications of fault signatures and associated faults features, collected at the Sheaon Harris Nuclear Generating Station, are presented in Appendix A. These fault signatures and fault features will be used to populate the AFS database of the FW-PHM Software Suite.

\subsection{Diagnosis Example}

The following discussion presents an example of diagnosis performed on an oil pump motor. Figure 9 shows a screen shot from the Diagnostic Advisor showing the different technologies and fault features that can be used to assess the health of an oil pump motor. Figure 10 shows the diagnosis result based on the selected inputs. The score column in Figure 10 indicates the likelihood of each possible fault diagnosis.

\begin{tabular}{|c|c|c|c|c|c|c|c|}
\hline Technology & Exam & Description & Query value & Current value & Timestamp & signature & source \\
\hline Lubricant/fluid Anslysis & Particle Content & $\begin{array}{l}\text { Assessment of a met alic particle content in lubricant } \\
\text { st a radial bearing location. }\end{array}$ & MARGIINAL & $N / A$ & $N / A$ & 8 & 8 \\
\hline Physical Integrity & Condition & Visual inspection for signs of wear & NORMAL & N/A & N/A & 8 & 8 \\
\hline Technology & Exam & Description & Query Value & Current Value & Timestamp & signature & Source \\
\hline Electrical Current & value & CURPENT SIGNATURE ANALYSIS & NOPNALL & $N / A$ & N/A & 8 & 8 \\
\hline Electrical Resistance & Value & CUREENT CHECKS TO FIND INSULATION PROBLEMS & AENOFMAL & $N / A$ & N/A & 8 & $\rho$ \\
\hline Physical Integrity & Condition & Inspection & NOPNALL & N/A & N/A & 8 & 8 \\
\hline Temperature & value & Winding Temperature & ABENOFMAL & $N / A$ & $\mathrm{~N} / \mathrm{A}$ & 8 & 8 \\
\hline vibration & Magnitude Yalue & YIBRATION MAGNITUDE & AENOFMAL & N/A & $\mathrm{N} / \mathrm{A}$ & 8 & 8 \\
\hline Technology & Exam & Description & Query value & Current value & Timestamp & signature & Source \\
\hline Acoustic Noise & value & Describe Tech Exam Type & N/A & $N / A$ & N/A & 8 & 8 \\
\hline Electrical Resistance & value & $\begin{array}{l}\text { Motor bearing insulation resistance check between ol } \\
\text { reservoir and bearing housing. }\end{array}$ & $\nabla$ & N/A & N/A & 8 & 8 \\
\hline Lubricant/fluid Analysis & Particle content & $\begin{array}{l}\text { Assessment of a metellic particle content in lubricant } \\
\text { at a radial bearing location. }\end{array}$ & $\nabla$ & $N / A$ & N/A & 8 & 8 \\
\hline Physical Integrity & Condition & Visual inspection for signs of wear & $\nabla$ & $N / A$ & $\mathrm{~N} / \mathrm{A}$ & 8 & 8 \\
\hline Temperature & value & $\begin{array}{l}\text { Assessment of a temperature value at radial bearing } \\
\text { loccation. }\end{array}$ & N/A & $N / A$ & N/A & 8 & 8 \\
\hline Vibration & Magritude Yalue & $\begin{array}{l}\text { Assessment of a vibration magnitude (time domain) } \\
\text { value at a radial bearing location. }\end{array}$ & N/A & $N / A$ & N/A & $\theta$ & $\rho$ \\
\hline
\end{tabular}

Figure 9. List of fault features for oil pump motor fault types. 


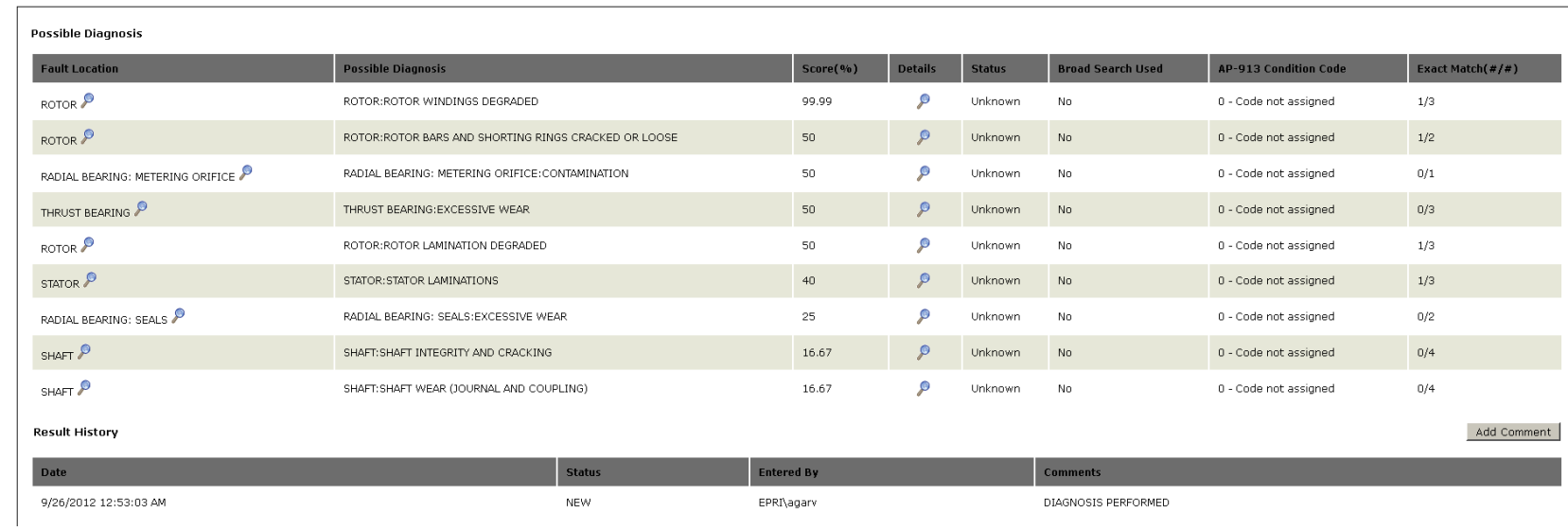

Figure 10. Possible diagnosis of oil motor pump using the FW-PHM.

\subsection{Benefits}

The current approach to assessing asset health is based on a series of testing and interpretation of results by subject matter experts. The FW-PHM software provides automated diagnosis and prognosis capabilities that are meant to streamline the diagnosis process. The software is unique in the sense that it standardizes the diagnostic and prognostic approach across assets based on fault signatures and fault features, generates a comprehensive diagnosis report, and allows information sharing between different NPPs via a master database.

The FW-PHM Diagnostic Advisor performs diagnosis based not only on the current value of the system, but also on historical records, plant operating conditions, and expert opinions. Based on the level of significance associated with each fault feature, the Diagnostic Advisor returns a set of possible faults along with a degree of confidence. This allows maintenance personnel to assess different fault possibilities. In addition, the software maintains online records including asset type, fault, diagnosis, and day of occurrence, which can be used to generate an asset health report.

Additionally, the FW-PHM RUL database and RUL advisor facilitate estimation of asset RUL. The initial set of prognostic models in the RUL database range from simple linear models to more advanced general path models. Based on the type of information available, RUL models can be selected to obtain an accurate estimate of asset RUL. 


\section{PILOT PROJECT STATUS}

EPRI and INL are teaming with Exelon Corporation to demonstrate the use of the FW-PHM Suite to monitor EDGs at the Braidwood Generating Station. Mohammed Yousuf, the Exelon Monitoring Program Manger, is serving as project coordinator for Exelon. Gary Deck, the Braidwood EDG System Engineer, is serving as a technical advisor. Team members from EPRI, INL, and Expert Microsystems travelled to Braidwood for a team meeting on September 6, 2012, to define the initial fault signatures for implementation. The EDGs installed at Braidwood are Cooper-Bessemer KSV 20-cylinder generators. 16-and 20-cylinder Cooper-Bessemer EDGs are installed in 31 plants at eight sites in the United States.

EPRI and INL are teaming with Duke Energy Progress to demonstrate the use of the FW-PHM Suite to monitor EDGs at the Shearon Harris Nuclear Generating Station. Greg Young, a nuclear monitoring program engineer, is serving as project coordinator from Duke Energy Progress. Mike Bodnar, the Shearon Harris GSU Transformer System Engineer, is serving as a technical advisor. Team members from EPRI, INL, and Expert Microsystems travelled to Shearon Harris for a team meeting on September 19, 2012. Shearon Harris is in the process of installing new GSU transformers, with built-in monitoring capabilities. 


\section{SUMMARY AND FUTURE PLANS}

This report presents the interim research activities associated with OLM of GSU Transformers. The different fault types in GSUs and features associated each fault type are identified and discussed. DGA and oil analysis are the primary technologies used to identify different fault types. EPRI and INL interacted with transformer experts from the Shearon Harris Nuclear Generating Station to capture multiple fault signatures based on DGA, laboratory testing, and oil analysis.

In FY-13, INL will continue to work with the Shearon Harris Nuclear Generating Station to populate the AFS database with GSU fault signatures. Different test scenarios will be developed and implemented to evaluate the ability of the Diagnostic Advisor in the FW-PHM Software Suite to identify the most relevant faults based on both complete and incomplete information. INL and EPRI will also assist the Shearon Harris Nuclear Generating Station with the implementation of the software. INL will initiate review of prognostic techniques to estimate the RUL of GSUs. 


\section{REFERENCES}

Bartley, W. H., (2003). Analysis of Transformer Failures. Proceedings of the $36^{\text {th }}$ Annual Conference on International Association of Engineering Insurers.

Bhumiwat, S. A., (2004). Insulation Condition Assessment of Transformer Bushings by means of Polarisation/Deploarisation Current Analysis. In Proceedings of IEEE International Symposium on Electrical Insulation, Indianapolis, USA.

Catterson, V.M., McArthur, S.D.J., Judd, M.D., and Zaher, A.S., (2008). Managing Remote Online Partial Discharge Data. IEEE Transactions on Power Delivery, vol. 23, no. 4, pp. $1754-1762$.

Coble, J., Strong, E., O’Reilly, S., and Hines, W., (2011). Prognosis of Remaining Useful Life for Large, Oil-Filled Transformers. ANS Winter Meeting, 2011.

Dong, X., (2002). Study of Power Transformer Abnormalities and IT Application in Power Systems. PhD Dissertation. Virginia Polytechnic Institute and State University, Virginia.

Duval, M., (2002). A Review of Faults Detectable by Gas-in-Oil Analysis in Transformers. IEEE Electrical Insulation Magazine, vol. 18, no. 3, 2002.

Electric Power Research Institute, (2005). Development of a New Acoustic Emission Technique for the Detection and Location of Gassing Sources in Power Transformers and LTCs. EPRI 1011708, Palo Alto, CA.

Electric Power Research Institute, (2006). Development and Testing of an On-line AE (Acoustic Emission)/Vibration Instrument. EPRI 1012344, Palo Alto, CA.

Electric Power Research Institute. (2006). Condition Monitoring and Diagnostics of Bushings, Current Transformers, and Voltage Transformers by Oil Analysis. EPRI 1012343, Palo Alto, CA.

Electric Power Research Institute. (2007). Condition Assessment Tools for Transformers: Development of Monitoring Systems. EPRI 1013929, Palo Alto, CA.

Electric Power Research Institute, (2011). EPRI Power Transformer Guidebook Development: The Copper Book. EPRI 1021892, Palo Alto, CA.

Electric Power Research Institute. (2011). Guideline for Online Monitoring of Nuclear Power Plants: Volume 2. EPRI 1023031, Palo Alto, CA.

EPRI, (2012) “Asset Fault Signature Requirements,” Software manual, 2012.

Hamrick, L., (2010). Dissolved Gas Analysis for Transformers. International Engineering Testing Association (NETA) World.

Hong, Y., Meeker, W.Q., and McCalley, J.D., (2009). Prediction of Remaining Life of Power Transformers based on Left Truncated and Right Censored Lifetime Data. The Annals of Applied Statistics, vol. 3, no. 2, pp. 857-879.

Human Factors International, www.hfi.com.

IEEE Standards, IEEE C57.104 (1978). IEEE Guide for the Detection and Determination of Generated Gases in Oil-Immersed Transformers and Their Relation to the Serviceability of the Equipment.

Judd, M.D., Yang, L., Bennoch, C.J., and Hunter, I.B.B., (2004). UHF Diagnostic Monitoring Techniques for Power Transformers. EPRI Substation Equipment Diagnostics Conference, New Orleans.

Lin, C.E., Ling, J.M., and Huang, C.L., (1993). An Expert System for Transformer Fault Diagnosis using Dissolved Gas Analysis. IEEE Transactions on Power Delivery, vol. 8, no. 1, pp. 231-238. 
Lybeck, N.J., Coble, J., Tawfik, M., and Bond, L.J., (2011). An Assessment of Integrated Health Management (IHM) Frameworks. $3^{\text {rd }}$ International Conference on NPP Life Management (PLiM) for Long Term Operations (LTO), IAEA-CN-194-031.

Ma. H., Saha, T.K., and Ekanayake, C., (2012). Statistical Learning Techniques and Their Applications for Condition Assessment of Power Transformers. IEEE Transactions on Dielectrics and Electrical Insulation, vol. 19, no.2, pp. 481-489.

Muthanna, K.T., Sarkar, A., Das, K., and Waldner, K., (2006). Transformer Insulation Life Assessment, IEEE Transactions on Power Delivery, vol. 21, no. 1, pp. 150-156.

Pamuk, N., and Uyaraglu, Y., (2010). The Analysis of Electrical and Mechanical Faults in PowerTransformers by Fuzzy Expert System. Scientific Research and Essays, vol. 5, no. 23, pp. 4018-4027.

Pradhan, M.K., and Ramu, T.S., (2005). On the Estimation of Elapsed Life of Oil-Immersed Power Transformers. IEEE Transactions on Power Delivery, vol. 20, no. 3, pp. 1962-1969.

Saha, T.K., (2003). Review of Modern Diagnostic Techniques for Assessing Insulation Condition in Aged Transformers. IEEE Transactions on Dielectrics and Electrical Insulation, vol. 10, no.5, pp. 903-917.

Shintemirov, A., Tang, W., and Wu, Q.H., (2009). Power Transformer Fault Classification Based on Dissolved Gas Analysis by Implementing Bootstrap and Genetic Programming. IEEE Transactions on Systems, Man, and Cybernetics - Part C: Applications and Reviews, vol. 39, no. 1, pp. 69-79.

Strong, E., Coble, J., O'Reilly, S., and Hines, W., (2011). Feasibility of Prognostics for Transformer Remaining Useful Life Predictions. MFPT: The Applied Systems Health Management Conference, Virginia. 


\section{Appendix A \\ GSU Fault Signatures}

\section{Winding Insulation Degradation}

Table A2. Winding Insulation Degradation Fault Signature - General Specification.

Describe in detail the asset type for which this fault signature is applicable.

GSU Transformers Winding Insulation Degradation

Describe the sources of the information used to specify this fault signature.

GSU Diagnostic Workshop at Shearon Harris Nuclear Generating Station, Raleigh, NC, September 19,2012

Name or briefly describe the fault type for this fault signature.

Loss of dielectric strength of the winding insulation

Describe the condition and/or mechanism of the fault and provide reference information.

Increase in oil moisture/acidity causes loss of dielectric strength, depolymerization of the paper, or reduction in oil dielectric strength

Describe any limitations on the applicability or relevance of this fault signature.

Winding insulation in all kinds of oil filled transformers using paper insulation

List the fault features indicating for the fault and attach a Fault Feature Specification for each.

Dissolved Gas Analysis: $\mathrm{H}_{2}$ level, $\mathrm{C}_{2} \mathrm{H}_{2}$ level, $\mathrm{CO}_{2} / \mathrm{CO}$ ratios

Oil Analysis: Measuring the $\mathrm{KOH}$ level of the oil. Dielectric strength of oil. Acidity and furans are products of degrading paper. Moisture in paper causes degradation but does not indicate for it.

Operating History: Over Temperature for long period.

Describe other faults that can cause this fault to occur.

Damage of winding insulation during maintenance activity

Water ingress into the oil, bladder tank leak in the conservator

History of over temperature for sustained period 
Describe other faults that can be caused by this fault.

Turn to turn shorts

Partial discharge and Arcing

Gassing

Describe the corrective actions that might remedy this fault.

Rebuild or replace

Provide contact information for the persons who prepared this fault signature.

Richard Rusaw, EPRI Project Manager: RRusaw@epri.com 
Table A3. Operating at High Temperature for Long Period. Technology: Operating History.

Describe the application of the fault feature for detecting the fault condition.

A history of high temperature operation indicates for the degradation of paper insulation

Describe the asset location where the data for assessing the fault feature is acquired initially.

GSU Transformer

Describe the technology used to acquire the data for assessing the fault feature.

Operating History Record

Describe the examination of the data that indicates whether or not the fault is present.

Time in Over temperature Operation

List all possible outcomes of the examination of the data (outcomes should be mutually exclusive).

Normal

Abnormal

Describe the effectiveness of this fault feature for detecting the fault condition.

$\square$ Very High; $\square$ High; $\otimes$ Medium; $\square$ Low; $\square$ Very Low

Provide reference information and examples for this fault feature.

Winding temperature more than $110 \mathrm{C}$ for time in excess of 24 hours; 8 hour $120 \mathrm{C}$; 1 hour $130 \mathrm{C}$

Top oil temperature more than $90 \mathrm{C}$ for time in excess of 24 hours; 8 hour $100 \mathrm{C}$; 1 hour $110 \mathrm{C}$ 


\section{Insulation Oil Degradation}

Table A4. Insulation Oil Degradation Fault Signature - General Specification.

Describe in detail the asset type for which this fault signature is applicable.

GSU Transformer Oil Degradation

Describe the sources of the information used to specify this fault signature.

GSU Diagnostic Workshop at Shearon Harris Nuclear Generating Station, Raleigh, NC, September 19,2012

Name or briefly describe the fault type for this fault signature.

Loss of dielectric strength of insulating oil

Describe the condition and/or mechanism of the fault and provide reference information.

Oil loses dielectric strength over time due to water and particulates contaminants, possibly thermal aging.

Describe any limitations on the applicability or relevance of this fault signature.

Insulating oil in transformers

List the fault features indicating for the fault and attach a Fault Feature Specification for each.

Oil analysis: dielectric strength value

Describe other faults that can cause this fault to occur.

NA

Describe other faults that can be caused by this fault.

Loss of the dielectric strength of the winding insulation

Describe the corrective actions that might remedy this fault.

Reclaimed or replace oil

Provide contact information for the persons who prepared this fault signature.

Richard Rusaw, EPRI Project Manager: RRusaw@epri.com 
Table A5. Loss of Dielectric Strength Oil Fault Feature - Technology: Oil analysis.

Describe the application of the fault feature for detecting the fault condition.

The dielectric strength of oil is determined directly by laboratory analysis

Describe the asset location where the data for assessing the fault feature is acquired initially.

Oil sampled from main oil tank

Describe the technology used to acquire the data for assessing the fault feature.

Oil Analysis

Describe the examination of the data that indicates whether or not the fault is present.

Measure of dielectric strength of the oil.

List all possible outcomes of the examination of the data (outcomes should be mutually exclusive).

Normal

Abnormal

Describe the effectiveness of this fault feature for detecting the fault condition.

$\bigotimes$ Very High; $\square$ High; $\square$ Medium; $\square$ Low; $\square$ Very Low

Provide reference information and examples for this fault feature.

ASTM D1816. Ref. FIST 3-31 gives threshold based on transformer rating 


\section{Insulating Oil Acidity}

Table A6. Insulation Oil Acidity Fault Signature - General Specification.

Describe in detail the asset type for which this fault signature is applicable.

GSU Transformer Oil Acidity

Describe the sources of the information used to specify this fault signature.

GSU Diagnostic Workshop at Shearon Harris Nuclear Generating Station, Raleigh, NC, September 19,2012

Name or briefly describe the fault type for this fault signature.

High acidity of insulating oil

Describe the condition and/or mechanism of the fault and provide reference information.

Oil is acidified over time due to water, aging and degradation of cellulose insulation

Describe any limitations on the applicability or relevance of this fault signature.

Insulating oil in transformers

List the fault features indicating for the fault and attach a Fault Feature Specification for each.

Oil analysis: dielectric strength value

Describe other faults that can cause this fault to occur.

Water ingress into oil; thermal degradation of winding insulation

Describe other faults that can be caused by this fault.

Loss of the dielectric strength of the winding insulation

Formation and precipitation of sludge on transformer internals (if $>0.4 \mathrm{mg} \mathrm{KOPH} / \mathrm{g}$ )

Describe the corrective actions that might remedy this fault.

Reclaim or replace oil

Provide contact information for the persons who prepared this fault signature.

Richard Rusaw, EPRI Project Manager: RRusaw@epri.com 
Table A7. Acidity of Oil Fault Feature - Technology: Oil analysis.

Describe the application of the fault feature for detecting the fault condition.

The acidity of oil is determined directly by laboratory analysis

Describe the asset location where the data for assessing the fault feature is acquired initially.

Oil sampled from tank

Describe the technology used to acquire the data for assessing the fault feature.

Oil Analysis

Describe the examination of the data that indicates whether or not the fault is present.

The level of $\mathrm{KOPH}$ is measured.

List all possible outcomes of the examination of the data (outcomes should be mutually exclusive).

Normal

Abnormal

Describe the effectiveness of this fault feature for detecting the fault condition.

$\bowtie$ Very High; $\square$ High; $\square$ Medium; $\square$ Low; $\square$ Very Low

Provide reference information and examples for this fault feature.

Ref. 5 of FIST 3-31. $0.2 \mathrm{mg} \mathrm{KOH} / \mathrm{g}$ is the upper limit. Reclaim or replace oil that reaches this level 


\section{Insulating Oil Contamination}

Table A8. Insulation Oil Contamination Fault Signature - General Specification.

Describe in detail the asset type for which this fault signature is applicable.

GSU Transformer Oil contamination with particulates

Describe the sources of the information used to specify this fault signature.

GSU Diagnostic Workshop at Shearon Harris Nuclear Generating Station, Raleigh, NC, September 19, 2012.

Name or briefly describe the fault type for this fault signature.

Particulate contamination of oil

Describe the condition and/or mechanism of the fault and provide reference information.

Particulates accumulate in oil over time

Describe any limitations on the applicability or relevance of this fault signature.

Insulating oil in transformers

List the fault features indicating for the fault and attach a Fault Feature Specification for each.

Oil analysis: interfacial tension test

Describe other faults that can cause this fault to occur.

Pump bearings, maintenance, paint, degradation of paper

Describe other faults that can be caused by this fault.

Loss of the dielectric strength of the winding insulation

Describe the corrective actions that might remedy this fault.

Reclaim or replace oil

Provide contact information for the persons who prepared this fault signature.

Richard Rusaw, EPRI Project Manager: RRusaw@epri.com 
Table A9. Interfacial Tension of Oil Fault Feature - Technology: Oil analysis.

Describe the application of the fault feature for detecting the fault condition.

The interfacial tension of oil is determined directly by laboratory analysis

Describe the asset location where the data for assessing the fault feature is acquired initially.

Oil sampled from tank

Describe the technology used to acquire the data for assessing the fault feature.

Oil Analysis

Describe the examination of the data that indicates whether or not the fault is present.

Measure the interfacial tension of the oil.

List all possible outcomes of the examination of the data (outcomes should be mutually exclusive).

Normal

Abnormal

Describe the effectiveness of this fault feature for detecting the fault condition.

$\bigotimes$ Very High; $\square$ High; $\square$ Medium; $\square$ Low; $\square$ Very Low

Provide reference information and examples for this fault feature.

Ref. 5 of FIST 3-31. 25 dynes/cm is the upper limit. Reclaim or replace oil that reaches this level 


\section{Loss of Dielectric Strength of Bushing}

Table A10. Loss of Dielectric Strength of Bushing Fault Signature - General Specification.

Describe in detail the asset type for which this fault signature is applicable.

GSU Transformer Bushing

Describe the sources of the information used to specify this fault signature.

GSU Diagnostic Workshop at Shearon Harris Nuclear Generating Station, Raleigh, NC, September 19, 2012.

Name or briefly describe the fault type for this fault signature.

Loss of bushing dielectric strength

Describe the condition and/or mechanism of the fault and provide reference information.

Loss of oil, ingress of water, damage to the porcelain, contaminants on the porcelain

Describe any limitations on the applicability or relevance of this fault signature.

Bushings in transformers

List the fault features indicating for the fault and attach a Fault Feature Specification for each.

Doble capacitance; Doble power factor; tap capacitance; tap current magnitude; tap current phase angle; Inspection for contaminant; Inspection for oil leaks; Inspection for oil level

Describe other faults that can cause this fault to occur.

NA

Describe other faults that can be caused by this fault.

Arcing and possibly transformer damage

Describe the corrective actions that might remedy this fault.

Refurbish or replace the bushing

Provide contact information for the persons who prepared this fault signature.

Richard Rusaw, EPRI Project Manager: RRusaw@epri.com 
Table A11. Doble Capacitance Fault Feature - Technology: Doble Analysis.

Describe the application of the fault feature for detecting the fault condition.

The capacitance from the lead to the ground

Describe the asset location where the data for assessing the fault feature is acquired initially.

Bushing lead and ground connectors

Describe the technology used to acquire the data for assessing the fault feature.

Doble measurement of Intelligent Diagnostic Device (IDD) online system

Describe the examination of the data that indicates whether or not the fault is present.

Measure capacitance during operation

List all possible outcomes of the examination of the data (outcomes should be mutually exclusive).

Normal

Doble condition codes for Abnormal dielectric strength

Describe the effectiveness of this fault feature for detecting the fault condition.

$\square$ Very High; $\otimes$ High; $\square$ Medium; $\square$ Low; $\square$ Very Low

Provide reference information and examples for this fault feature.

IDD Bushing User Guide. 


\section{Oil Pump Motor Performance Loss}

Table A12. Oil Pump Motor Performance Loss - General Specification.

Describe in detail the asset type for which this fault signature is applicable.

GSU Insulating Oil Pump Motor (pump and motor? Or pump/motor combination?)

Describe the sources of the information used to specify this fault signature.

GSU Diagnostic Workshop at Shearon Harris Nuclear Generating Station, Raleigh, NC, September $19,2012$.

Name or briefly describe the fault type for this fault signature.

Oil pump motor is not running or not running to service specifications

Describe the condition and/or mechanism of the fault and provide reference information.

The pump motor is not running or not running to service specifications

Describe any limitations on the applicability or relevance of this fault signature.

Oil pump motor on transformers. $480 \mathrm{~V} 3$ phase AC

List the fault features indicating for the fault and attach a Fault Feature Specification for each.

Ground Fault (alarm) (can apply to pump and fan motors)

Motor current: No, low or high current (alarm) (can apply to pump and fan motors)

Temperature: Top Oil Temperature

Temperature: Winding

Inspection: Motor Condition(can apply to pump and fan motors)

Gassing and Vibration

Describe other faults that can cause this fault to occur.

Loss of electric power; bad breaker

Describe other faults that can be caused by this fault.

Overheating of oil and windings; pressure increase in tank

Describe the corrective actions that might remedy this fault.

Restore power; repair or replace motor

Provide contact information for the persons who prepared this fault signature.

Richard Rusaw, EPRI Project Manager: RRusaw@epri.com 
Table A13. Motor Current Abnormal Value: Fault Feature.

Describe the application of the fault feature for detecting the fault condition.

Abnormal motor current

Describe the asset location where the data for assessing the fault feature is acquired initially.

Motor lead current probe. CT with one phase lead running through it

Describe the technology used to acquire the data for assessing the fault feature.

Current transformer inductively coupled to the current flowing through a motor lead

Describe the examination of the data that indicates whether or not the fault is present.

Determine if current flow in lead is above or below a maximum or minimum value, respectively.

List all possible outcomes of the examination of the data (outcomes should be mutually exclusive).

Normal

Abnormal

Describe the effectiveness of this fault feature for detecting the fault condition.

$\square$ Very High; $\otimes$ High; $\square$ Medium; $\square$ Low; $\square$ Very Low

Provide reference information and examples for this fault feature. 
Table A14. Motor Insulation Resistance Megger Inspection: Fault Feature.

Describe the application of the fault feature for detecting the fault condition.

Megger Inspection of motor

Describe the asset location where the data for assessing the fault feature is acquired initially.

Pump motor (can apply to fan motor)

Describe the technology used to acquire the data for assessing the fault feature.

Inspection of motor using Megger tester.

Describe the examination of the data that indicates whether or not the fault is present.

Value of insulation resistance lower than specification

List all possible outcomes of the examination of the data (outcomes should be mutually exclusive).

Normal

Abnormal (low)

List in order of increasing confidence the outcomes of the examination that indicate for this fault.

Abnormal

Describe the effectiveness of this fault feature for detecting the fault condition.

$\square$ Very High; $\bigotimes$ High; $\square$ Medium; $\square$ Low; $\square$ Very Low

Provide reference information and examples for this fault feature.

Megger Company User guide or maintenance guide 